\title{
Salicylic Acid Determines Differential Senescence Produced by Two Turnip mosaic virus Strains Involving Reactive Oxygen Species and Early Transcriptomic Changes
}

\author{
Carlos Augusto Manacorda, ${ }^{1}$ Carmen Mansilla, ${ }^{2}$ Humberto Julio Debat, ${ }^{3}$ Diego Zavallo, ${ }^{1,4}$ \\ Flora Sánchez, ${ }^{2}$ Fernando Ponz, ${ }^{2}$ and Sebastián Asurmendi ${ }^{1,4}$ \\ ${ }^{1}$ Instituto de Biotecnología, CICVyA, INTA Castelar, Dr. N. Repetto y Los Reseros s/n, CP 1686 Hurlingham, Buenos Aires, \\ Argentina; ${ }^{2}$ Centro de Biotecnología y Genómica de Plantas, CBGP (UPM-INIA). Autopista M40, km 38. Campus \\ Montegancedo, Pozuelo de Alarcón, 28223 Madrid, Spain; ${ }^{3}$ Instituto de Patología Vegetal (IPAVE), Centro de Investigaciones \\ Agropecuarias (CIAP), Instituto Nacional de Tecnología Agropecuaria (INTA), Camino 60 cuadras Km 5,5, X5020ICA \\ Córdoba, Argentina; ${ }^{4}$ Consejo Nacional de Investigaciones Científicas y Técnicas (CONICET,) Buenos Aires, Argentina
}

Submitted 3 July 2013. Accepted 5 August 2013.

Losses produced by virus diseases depend mostly on symptom severity. Turnip mosaic virus (TuMV) is one of the most damaging and widespread potyvirus infecting members of the family Brassicaceae, including Arabidopsis thaliana. We used JPN1 and UK1 TuMV strains to characterize viral infections regarding symptom development, senescence progression, antioxidant response, reactive oxygen species (ROS) accumulation, and transcriptional profiling. Both isolates, despite accumulating similar viral titers, induced different symptomatology and strong differences in oxidative status. Early differences in several senescenceassociated genes linked to the ORE1 and ORS1 regulatory networks as well as persistent divergence in key ROS production and scavenging systems of the plant were detected. However, at a later stage, both strains induced nutrient competition, indicating that senescence rates are influenced by different mechanisms upon viral infections. Analyses of ORE1 and ORS1 levels in infected Brassica juncea plants showed a similar pattern, suggesting a conserved differential response to both strains in Brassicaceae spp. Transcriptional analysis of the ORE1 and ORS1 regulons showed similarities between salicylic acid (SA) response and the early induction triggered by UK1, the most severe strain. By means of SA-defective NahG transgenic plants, we found that differential senescence progression and ROS accumulation between strains rely on an intact $\mathrm{SA}$ pathway.

Plant viruses cause important losses worldwide in economically relevant crops (Scholthof et al. 2011). The development of virus symptoms is complex and varies depending on various

H. J. Debat and D. Zavallo contributed equally to this work and should jointly be considered third authors.

Corresponding author: S. Asurmendi; Fax: +(5411) 4621 0199; E-mail: asurmendi.sebastian@inta.gob.ar

* The $\boldsymbol{e}$-Xtra logo stands for "electronic extra" and indicates that five supplementary tables and four supplementary figures are published online. Also that Figures 1, 2,3, 5, and 6 appear in color online.

(C) 2013 The American Phytopathological Society aspects such as plant developmental status at infection, environmental conditions, and virus combinations, even strain, within a particular host. Symptoms include plant stunting, changes in leaf morphology, tissue chlorosis, necrosis, and sometimes plant death (Hull 2002). Viruses use various strategies to coopt cellular resources of compatible host plants to promote their infections. In compatible hosts, viral invasion triggers numerous biochemical and physiological changes in cells, tissues, and even whole plants (Maule et al. 2002). Viral infections induce massive transcriptomic changes in the host, including an important subset of genes related to reactive oxygen species (ROS) production and scavenging, salicylic acid (SA) signaling, and senescence, among others (Golem and Culver 2003; Hillung et al. 2012; Huang et al. 2005; Whitham et al. 2006). As a result, early senescence is one of the possible outcomes of compatible viral infections (Ascencio-Ibanez et al. 2008).

Senescence begins with chloroplast dismantling followed by catabolism of macromolecules (Guo and Gan 2005; Hopkins et al. 2007; Lim et al. 2007) and membrane destabilization (Rolny et al. 2011). Leaf senescence is a fine-tuned process that involves cell death for recycling and reuse of valuable resources (Gan and Amasino 1997) that are reallocated from the senescing leaf to growing tissues (Buchanan-Wollaston 1997; Hortensteiner and Feller 2002). Senescence is triggered by age and development (Hensel et al. 1993) and responds to endogenous signals (Riefler et al. 2006). However, it is also influenced by both abiotic and biotic stressors (Butt et al. 1998; Miller et al. 1999; Navabpour et al. 2003; Pic et al. 2002; Weaver et al. 1998; Xiong et al. 2005). In this regard, diverse developmental and environmental stimuli, including pathogen attack, trigger the accumulation of intracellular ROS and, among them, hydrogen peroxide $\left(\mathrm{H}_{2} \mathrm{O}_{2}\right)$ is an apparent signaling element in the regulation of senescence (Balazadeh et al. 2010b, 2011; Munne-Bosch and Alegre 2002; Wu et al. 2012). Senescence determines changes in expression of many genes, including those of regulatory function (Balazadeh et al. 2010b, 2011; Buchanan-Wollaston et al. 2005). Consistently upregulated transcription factors (TF) are included in the category of senescence-associated genes (SAG).

Many SAG also respond to environmental stress and, therefore it can be hypothesized that some of them serve as integrators of the different signaling pathways that control stress 
responses or age-dependent senescence (Balazadeh et al. 2010a; Weaver et al. 1998). NAC and WRKY families are among the largest groups of senescence-related TF (Balazadeh et al. 2008; Breeze et al. 2011) and play important roles in leaf senescence. Several NAC TF are involved in important networks of stressand age-induced senescence; mainly ORE1 (Balazadeh et al. 2010a; Kim et al. 2009), its paralog ORS1 (Balazadeh et al. 2011), and JUB1 (Wu et al. 2012). Whereas ORE1 is regulated by microRNA 164 (miR164), ORS1 is not. Promoter analyses revealed that ORE1 and ORS1 share common regulatory elements in Arabidopsis thaliana, and promoter conservation across different Brassicaceae spp. is very high (Balazadeh et al. 2011). Most of these elements were predicted to participate in stress, wound, or SA responses, including W-box and WRKY box. Furthermore, ORE1, ORS1, and JUB1 respond to $\mathrm{H}_{2} \mathrm{O}_{2}$ differently (Balazadeh et al. 2011; Wu et al. 2012). The ORE1 and ORS1 regulons share only a subset of downstream co-regulated genes (Balazadeh et al. 2011), suggesting that these senescenceassociated NAC TF differ in their regulation. The WRKY TF family has 74 members in Arabidopsis and is involved in the regulation of plant defense and senescence. Numerous WRKY group III TF, including WRKY70, have been functionally characterized as leaf senescence regulators (Besseau et al. 2012; Miao et al. 2004; Ulker et al. 2007). Specifically, WRKY70, an $\mathrm{H}_{2} \mathrm{O}_{2}$-insensitive factor with SA-dependent expression during senescence, participates in the integration of hormone signaling in defense processes (Li et al. 2004, 2006).

Nodes of convergence between senescence signals and pathogen defense are essential because the same hormones frequently play a key role in orchestrating both processes. Among them, SA plays a central role in plant defense signaling. It is required for the recognition of pathogen-derived components and subsequent establishment of local and systemic resistance (Hammond-Kosack and Jones 1996; Ryals et al. 1996; Tsuda et al. 2008). SA accumulation is induced upon stress conditions and treatments with pathogens or pathogen-derived elicitors (Sharma and Davis 1997; Tsuda et al. 2008; Vernooij et al. 1994). Consistently, NahG transgenic plants harboring the $n a h G$ gene (which encodes a bacterial SA-degrading enzyme) have increased susceptibility to both cellular and viral pathogens (Delaney et al. 1994; Kachroo et al. 2000).

Among the best studied biotic stresses known to involve SA are viral infections (Vlot et al. 2009). Although typical of incompatible plant-virus pathosystems (Ryals et al. 1996), involvement of SA in plant virus response has been reported for systemic, compatible interactions, including Arabidopsis and Turnip mosaic virus (TuMV) (Whitham et al. 2003).

Although several studies have compared the differential effects of the same virus in diverse ecotypes or cultivars of the same species (Hillung et al. 2012; Lalic et al. 2010; Martin Martin et al. 1999; Pagan et al. 2008), studies evaluating the outcome of infections of related virus strains on the same species are scarce and limited (Hakmaoui et al. 2012; Hanssen et al. 2011).

Here, we use JPN1 and UK1 strains of TuMV (a potyvirus that infects members of the Brassicaceae family) (Nguyen et al. 2013; Sanchez et al. 1998) to infect A. thaliana and Brassica juncea to characterize the hosts throughout the infectious processes. We focused our analysis regarding differences in host symptoms development, antioxidant species, and ROS accumulation and transcriptomic changes of relevant SAG.

\section{RESULTS}

\section{Different TuMV strains induce distinct symptoms in Arabidopsis.}

To compare the phenotypic responses of Arabidopsis plants to two TuMV strains, $A$. thaliana (ecotype Col-0) plants were inoculated with either UK1 or JPN1 isolates of TuMV. These two isolates are representative of two different genetic strains of the virus; namely, MB and MR, respectively (Sanchez et al. 2003). For simplicity, we will refer to the isolates as "strains: hereinafter. A detailed comparison of the main differences between the two strains is to be published elsewhere. Overall, the developmental plan of infected plants was altered comparing strains and between strains and noninfected plants. TuMV UK1 interfered strongly with the normal succession of developmental events. TuMV JPN1 did not arrest development; rather, it altered it quantitatively, affecting branching, flowering pattern, and some other important developmental features. For the purpose of this article, a description of the differential responses related to aspects specific to this study is presented The phenotypic responses were evaluated by recording the development of typical TuMV symptoms at several days postinoculation (DPI) (Fig. 1A). Whereas, at 4 DPI, no symptoms were visible, twisting in systemic uppermost leaves was observed at 6 DPI, especially in leaves forming a small angle with the inoculated one. By 11 DPI, a more pronounced twisting was observed in young leaves and a flowering delay could be detected in plants inoculated with any strain when compared with mock-inoculated plants. Interestingly, at this point, JPN1- and UK1-inoculated plants started to display different symptoms. UK1-inoculated plants showed a precocious yellowing on rosette leaves and dark staining on some older leaves. At 16 DPI, differences between plants became more pronounced. Whereas JPN1-infected plants succeeded in bolting and rosette leaves stayed green (although a degree of twisting could be seen), UK1-infected plants showed further yellowing of the rosette and developed dwarfed, curled leaves, resulting in severe stunting, and bolting was arrested (Fig. 1A). These differences were accentuated later and, by 21 DPI, UK1 provoked leaf death and a general yellowing of the rosette. At 27 DPI, both viruses exhibited clear senescence acceleration when compared with mock-inoculated plants but only UK1 arrested bolt emergence.

Viral RNA accumulation was measured in these plants by means of a TuMV-specific quantitative reverse-transcription polymerase chain reaction (qRT-PCR) assay on RNA extracts from pooled systemic, uppermost leaves (Fig. 1B). Rather similar amounts of viral RNA were detected in both groups of infected plants. UK1 accumulated at a slightly higher level at 4 and 10 DPI. However no difference in viral load was detected at $16 \mathrm{DPI}$ (Fig. 1B, white bars).

\section{The senescence process is highly delayed in JPN1-infected compared with UK1-infected plants.}

To analyze and compare the senescence process triggered by both strains, we recorded the progression of senescence on the fifth rosette leaves (Fig. 2A). No evident differences could be observed at 4 and 11 DPI between treatments (Mock, UK1, and JPN1). However, by 16 DPI, UK1-infected plants showed clear yellowing on their fifth leaves, whereas JPN1 induced very mild senescence symptoms. Differences between treatments accentuated at 21 DPI, when UK1 provoked advanced senescence symptoms, JPN1-infected leaves showed tip yellowing, and mock-inoculated leaves presented very mild senescence symptoms. At 27 DPI, virus-infected fifth leaves were fully necrotic. Additionally, as early as 16 DPI, UK1-infected leaves exhibited purplish and reddish coloration, which is commonly related to anthocyanins in senescing leaves (Archetti et al. 2009). This pattern was further accentuated at 21 DPI but was barely detected in JPN1- or mock-treated samples until 27 DPI.

To further understand the comparative senescence process, we determined physiological senescence markers through the infectious process (Fig. 2B to F). One such marker is loss of 
fresh weight. No significant differences were detected between treatments at 16 DPI when sampled leaves reached maximum weight. At 21 DPI, however, virus-infected samples accelerated their loss of fresh weight, predominantly UK1-infected samples compared with JPN1 $(P<0.05)$ and mock $(P<0.001)$ (Fig. 2B). At 27 DPI, infected leaves had almost reached full senescence.

Chlorophyll levels (Fig. 2C) were significantly lower in UK1-infected samples as early as 11 DPI, when no yellowing phenotype or fresh weight reduction could yet be seen (Fig. $2 \mathrm{~A}$ and $\mathrm{B})$. JPN1 induced statistically significant differences with mock only after 21 DPI.

Anthocyanins are flavonoid compounds induced during senescence (Archetti et al. 2009). We monitored their accumulation over time (Fig. 2D). As expected, at 21 DPI, pigment accumulation increased from previously almost undetectable levels in the mock group. JPN1 induced a slightly earlier accumulation of anthocyanins, although not statistically different from mock-inoculated samples even at 21 DPI. However, by 16 DPI, UK1 provoked an abrupt accumulation of anthocyanins, which remained sevenfold higher than those of mock- inoculated samples at 21 DPI. Although anthocyanin content was expected to rise in a senescence-driven manner, the sharp increase of this flavonoid in UK1-infected samples was notable. Anthocyanins are induced by several stressors (Gould 2004) which trigger oxidative stress. Therefore, we argue that their antioxidant role could at least partially explain the increase in their accumulation.

Carotenoids are antioxidant molecules also induced by oxidative stress (Kim et al. 2008; Kim et al. 2012). No significant differences in relative carotenoid concentrations between treatments were found across the experiment (Fig. 2E). Nevertheless, a particular trend could be detected in UK1-inoculated samples when compared with mock- or JPN1-inoculated samples. Intra-treatment analysis revealed that only the UK1 group exhibited a consistent rise in relative carotenoid concentration between 11 and 21 DPI (+77\%). By 27 DPI, drying of the virusinfected leaves (Fig. 2A) limited further analysis. Interestingly, when calculating the chlorophylls/carotenoids ratio (Fig. $2 \mathrm{~F}$ ) for all treatments, clear differences were detected. This ratio was three- and fourfold higher in UK1- compared with mockinoculated samples at 16 and $21 \mathrm{DPI}$, respectively. The JPN1

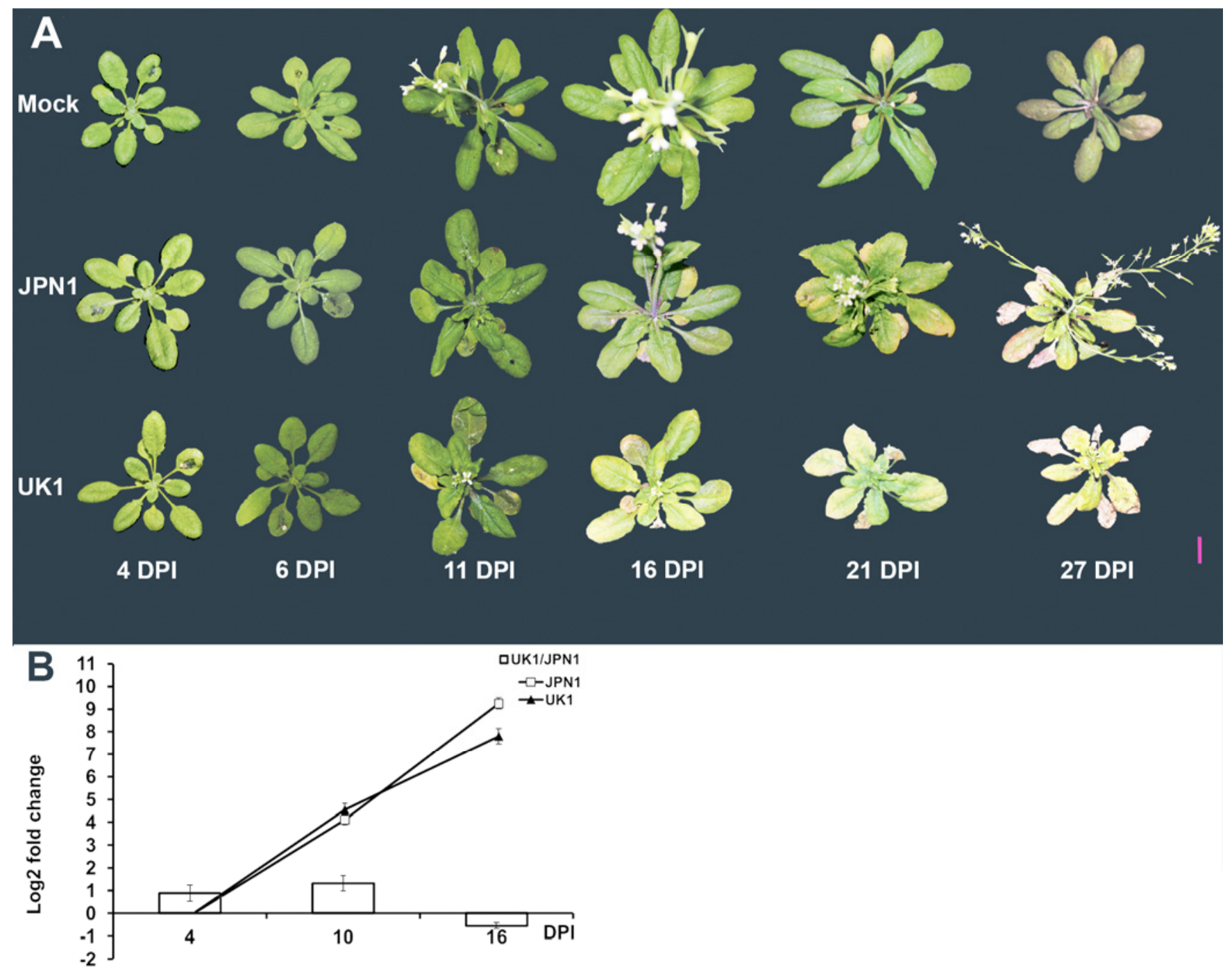

Fig. 1. Phenotypic characterization of two Turnip mosaic virus (TuMV) strains infecting Arabidopsis. A, Appearance of the Arabidopsis thaliana Col0 plants following mock inoculation (upper panel) or JPN1 or UK1 TuMV strain infection (lower panels). Bolts were cut before recording mock-inoculated plants at 21 and 27 days postinoculation (DPI) for clarity. Bar $=1 \mathrm{~cm}$. B, Relative viral loads for JPN1- and UK1-inoculated plants at three different DPI obtained using a TuMV-specific quantitative reverse-transcription polymerase chain reaction assay. Comparisons were made between viruses (white bars) or within a virus (solid lines). For both viruses in this latter case, 4 DPI was arbitrarily set as 0 . Error bars represent standard error. 
group showed minor differences with mock throughout the experiment. Taken together, these results suggest a particular oxidative status induced by UK1 infection.

\section{UK1 but not JPN1 induces ROS accumulation in systemically infected tissues.}

Considering the natural processes of viral replication and spread from the initial inoculation sites, we hypothesized that putative early systemic redox changes should be first detected in upper, younger leaves. To find the most suitable leaf for further biochemical and molecular analysis, we employed TuMV harboring a green fluorescent protein gene (TuMV-GFP, engineered based on UK1) (Sanchez et al. 1998; Tourino et al. 2008) to follow the progression of the infection in detail. No fluorescence was detected in systemic tissues at 4 DPI (Supplementary Fig. S1). By 6 DPI, however, viral particles had reached leaves 8, 9, 10 , and 11 . At $8 \mathrm{DPI}$, only leaf 11 was fully fluorescent, which indicates that this leaf is a primary sink tissue for viral particles coming from the inoculated third leaf. Leaf 11 from 4 to 21 DPI for all treatments is shown in Figure 3A. As expected, UK1
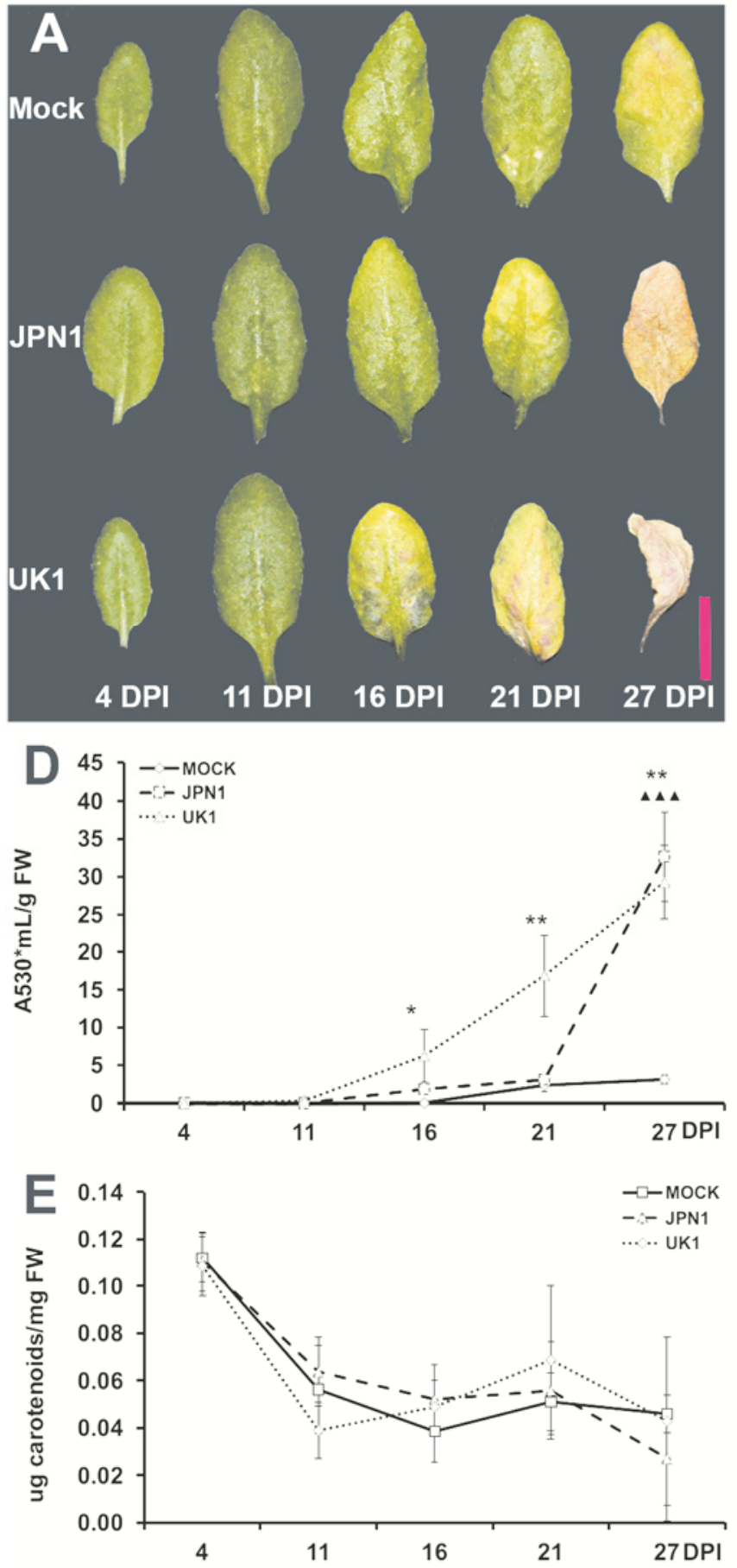
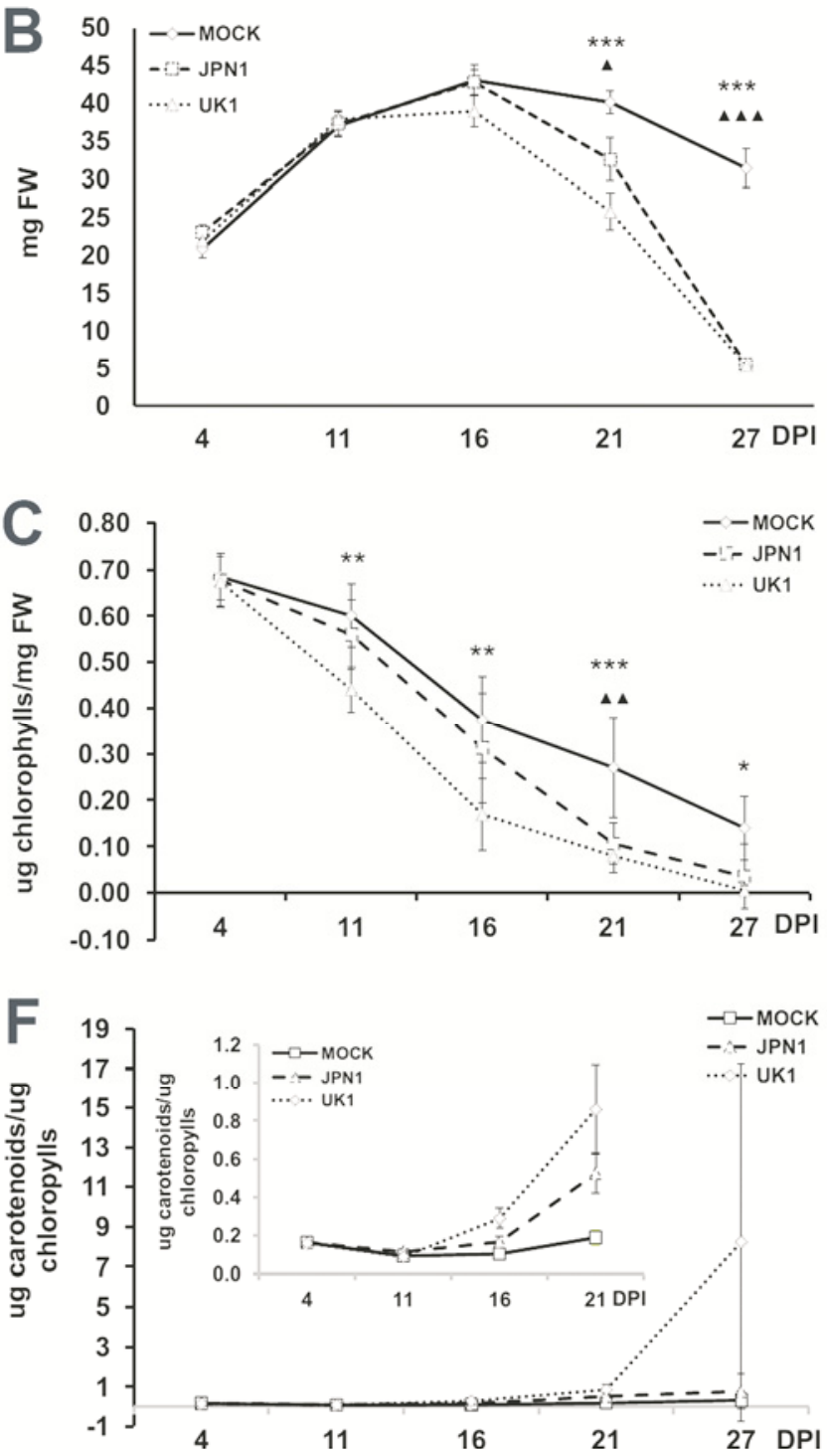

Fig. 2. Comparative senescence progression in Turnip mosaic virus (TuMV)-infected Col0 plants. A, Representative leaf 5 harvested from plants at 4 to 27 days postinoculation (DPI) inoculated with buffer only (mock) or JPN1 or UK1 TuMV strains. Bar $=1 \mathrm{~cm}$. B, Fresh weight measurements of the sampled leaves during the experiment; $18 \leq n \leq 32$ leaves per treatment and DPI. C, Total chlorophylls; $\mathbf{D}$, anthocyanins; and $\mathbf{E}$, carotenoids content and $\mathbf{F}$, carotenoid/chlorophyll ratio in leaf 5 of mock- and virus-inoculated plants across the experiment; $4 \leq n \leq 11$ leaves per treatment and DPI. Asterisks and small triangles indicate significant differences between mock/UK1- and mock/JPN1-inoculated samples, respectively. One-way analysis of variance with Tukey's post-test was performed. Error bars represent standard error. 
accelerated senescence symptoms, mimicking the response of leaf 5. However, unlike leaf 5, viral infections reduced the maximum growth of leaf 11 (Fig. 3B). Moreover, JPN1-infected leaves continued to grow until 21 DPI whereas UK1 completely arrested growth beyond 11 DPI (Fig. 3B; Table 1). These results are in agreement with our preliminary observations (F. Ponz and F. Sánchez, unpublished results). Because leaf 11 had not emerged at 0 DPI, the impact of the viral infection on its development should be paramount as a principal sink of the inoculated third leaf. Hereinafter, we chose leaf 11 to study molecular changes throughout the infection.

The increase in antioxidants could be attributed to a higher accumulation of ROS, including superoxide $\left(\mathrm{O}_{2}^{-}\right)$and $\mathrm{H}_{2} \mathrm{O}_{2}$, which are common in some responses to biotic stresses that could modify the redox status of the cells (Grosskinsky et al. 2012). To determine the relative accumulation of $\mathrm{H}_{2} \mathrm{O}_{2}$ and $\mathrm{O}_{2}{ }^{-}$, 3,3-diaminobenzidine (DAB) and nitro blue tetrazolium chloride (NBT) staining techniques were performed, respectively. A statistically significant overaccumulation of $\mathrm{H}_{2} \mathrm{O}_{2}$ from 11 to 21 DPI induced by UK1 is shown in Figure 4A; strikingly, JPN1-infected samples did not show any differences with the controls. NBT staining (Fig. 4B) exhibited a similar pattern.
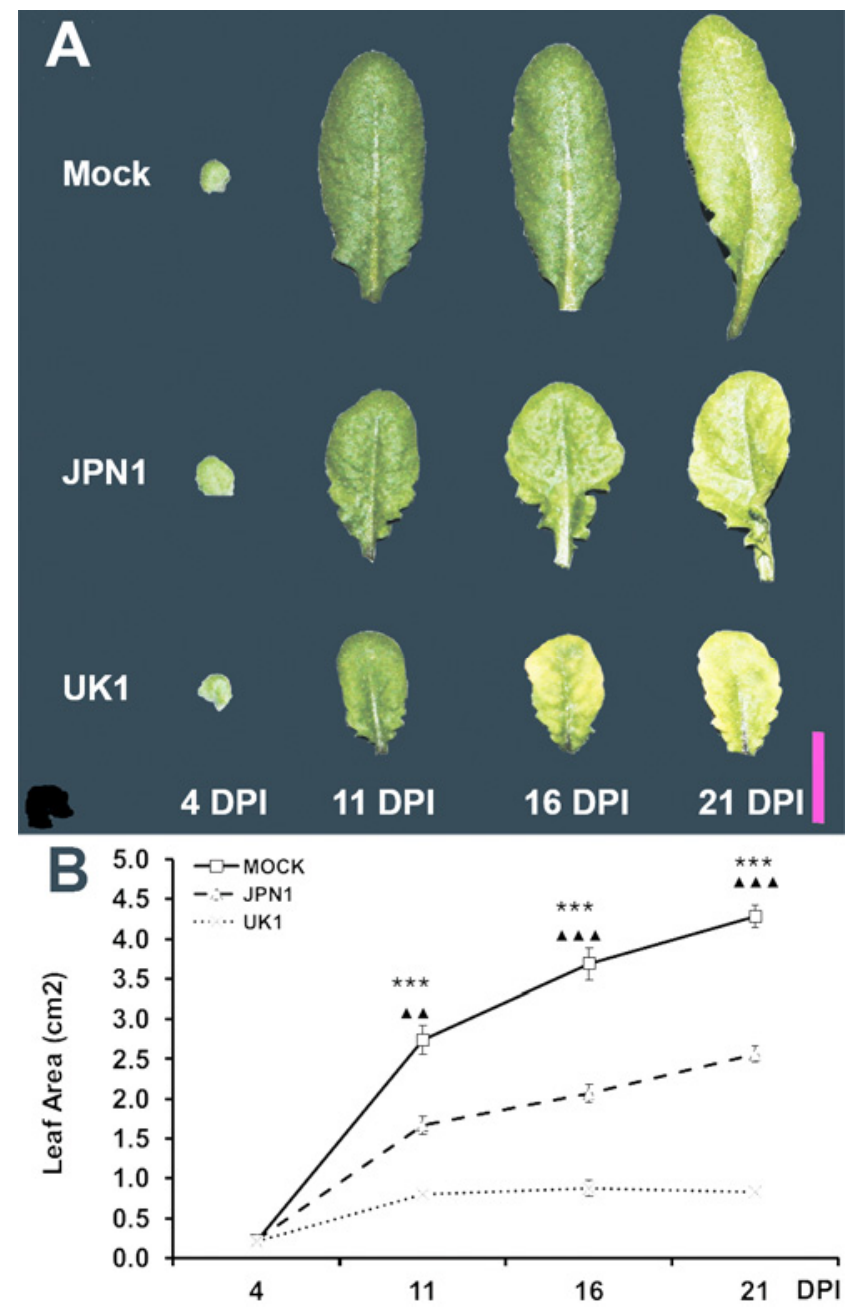

Fig. 3. A, Representative recording and $\mathbf{B}$, leaf area growth of Col0 leaf 11 sampled at 4 to 21 days postinoculation (DPI) inoculated with buffer only (mock) or JPN1 or UK1 Turnip mosaic virus (TuMV) strains; $20 \leq$ $n \leq 34$ leaves per treatment and DPI. Asterisks and small triangles indicate significant differences between mock/UK1- and mock/JPN1-inoculated samples, respectively. Kruskal-Wallis nonparametric test with Dunn's post-test was performed. Error bars represent standard error. Bar = $1 \mathrm{~cm}$.
Key genes in senescence, oxidative stress, and hormone response are differentially regulated upon JPN1 and UK1 infection.

Transcript accumulation of key genes in senescence, oxidative stress, and hormone response were assayed by qRT-PCR on leaf 11 at 4, 10, and 16 DPI (Fig. 5). The complete list of analyzed transcripts and the respective fold changes in their accumulation following viral infections is shown in Supplementary Table S1. Given the importance of ORE1 and ORS1 in senescence and oxidative stress, both genes were assayed. Other genes were selected on the basis of their response to relevant biotic and abiotic stimuli, predicted SAG nature, or strong dependence on ORE1/ORS1 regulation (Balazadeh et al. 2010a, 2011). Results of the assays on these genes are summarized in Figure 5A. Few analyzed genes showed significant expression changes in JPN1-infected samples until 16 DPI, when senescence is already an ongoing process. By contrast, UK1 induced profound changes in gene expression from the

Table 1. Intra-treatments statistic analysis of Col0 leaf 11 area growth at 4 to 21 days postinoculation (DPI) ${ }^{\mathrm{a}}$

\begin{tabular}{lccc}
\hline Column 1 & Mock & JPN1 & UK1 \\
\hline 4 DPI vs. 11 DPI & $* * *$ & $* * *$ & $* * *$ \\
4 DPI vs. 16 DPI & $* * *$ & $* * *$ & $* * *$ \\
4 DPI vs. 21 DPI & $* * *$ & $* * *$ & $* * *$ \\
11 DPI vs. 16 DPI & $\mathrm{ns}$ & $\mathrm{ns}$ & $\mathrm{ns}$ \\
11 DPI vs. 21 DPI & $* * *$ & $* * *$ & $\mathrm{~ns}$ \\
16 DPI vs. 21 DPI & $\mathrm{ns}$ & $\mathrm{ns}$ & $\mathrm{ns}$ \\
\hline
\end{tabular}

a $20 \leq n \leq 34$ for each treatment and time point; ns = no significant statistical differences between the time points compared within a given treatment.
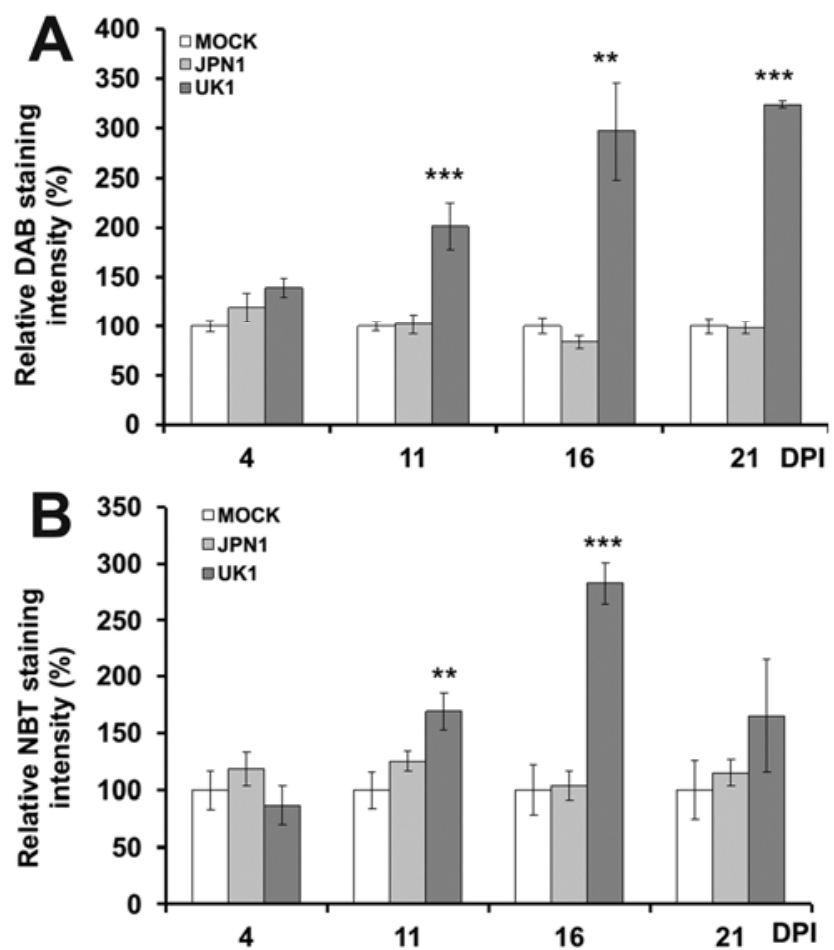

Fig. 4. $\mathrm{H}_{2} \mathrm{O}_{2}$ and $\mathrm{O}_{2}^{-}$overaccumulation in $\mathrm{UK} 1$-infected systemic $\mathrm{Col} 0$ leaves. A, Relative quantification of 3,3-diaminobenzidine staining on 11 th leaves. Individual intensity values were normalized to mockinoculated controls at each day postinoculation (DPI) analyzed. Mean values were calculated for mock-inoculated controls (white bars) and JPN1- and UK1-infected samples (light and dark gray bars, respectively). B, Same as in A for quantification of nitro blue tetrazolium chloride staining; $3 \leq n \leq 11$ leaves per treatment and DPI. One-way analysis of variance with Tukey's post-test were performed. Error bars represent standard error. 
beginning of the infection at $4 \mathrm{DPI}$, when no developmental symptoms or differential accumulation of ROS could yet be detected (Figs. 3A and 4). This pattern was mimicked at 10 DPI. By 16 DPI, both strains induced the overaccumulation of most of these selected SAG, including ORE1, although alterations were more pronounced with UK1. Nonetheless, divergences between JPN1- and UK1-driven changes are not only time dependent or quantitative but also qualitative in nature. The pattern of accumulation of Peroxidase 71 (At5g64120), a cell-wall peroxidase which produces ROS (Rouet et al. 2006), was particularly interesting. Cell-wall peroxidases are implicated in ROS production in plant defense (Bindschedler et al. 2006). Moreover, the production of ROS is a hallmark of successful pathogen recognition and activation of plant defenses and is typically apoplastic (Torres 2010). Despite its strong and sustained induction from 4 to 16 DPI in UK1 samples, JPN1 did not have any effect on the accumulation of this transcript. However, PDF1.4, a defense-related gene induced by viral infections (Ascencio-Ibanez et al. 2008), is also induced at early stages in JPN1-infected plants, indicative of strain recognition. Surprisingly, the ORE1 paralog ORS1 was downregulated at 16 DPI following both viral infections. Thus, we inoculated $B$. juncea plants with both strains to test the extent and conservation of these results in other TuMV-susceptible host. The accumulation patterns of both analyzed genes were similar to those of A. thaliana (Supplementary Fig. S2); ORE1 overaccumulated earlier in UK1-infected samples and ORS1 was downregulated at 16 DPI in all virus-infected samples.

Regarding Arabidopsis, the observed increase in $\mathrm{O}_{2}^{-}$accumulation in UK1-infected samples could be attributed to a misregulation of the detoxification mechanisms of the cell. Copper-zinc superoxide dismutases (CSDs) are of paramount importance in the enzymatic defense system against $\mathrm{O}_{2}{ }^{-}$. MiR398 targets cytosolic CSD1 and chloroplastic CSD2 and a copper chaperone for superoxide dismutase (CCS1) (Beauclair et al. 2010; Chu et al. 2005; Sunkar et al. 2006) but not the CCS1-independent peroxisomal CSD3 (Huang et al. 2012). The impact of viral infections on transcript accumulation of these five genes is shown in Figure 5B. Remarkably, at $10 \mathrm{DPI}$, the CSD2 transcript level is not changed in UK1 in contrast to the more than twofold increase observed in JPN1; furthermore, the negative regulator miR398 is increased almost sixfold in UK1.

Nutrient stress and hormone disarray are other well-known outcomes of viral infections. APS1 and PHO2 mRNAs are downregulated under sulfate and phosphate starvation, respectively (Fujii et al. 2005; Jones-Rhoades and Bartel 2004). Copper is crucial in plant protection against ROS (Burkhead et al. 2009) and its deprivation induces miR397 and miR408 (AbdelGhany and Pilon 2008). The accumulation of these transcripts under viral infections is compared in Figure 5C, showing notably lower levels of PHO2 in infected samples. Modulation of plant hormone networks, including auxin, abscisic acid, and jasmonic acid (JA) pathways, has been reported following pathogen attack (Zhang et al. 2011). To test for important genes involved in auxin signaling pathways, ARF8 and TIR1 levels were assayed (Fig. 5C). Although statistically significant differences between treatments were detected, no clear pattern emerged from these comparisons. TCP4 TF directly regulates lipoxygenase (LOX)2, a chloroplast-localized enzyme that is responsible for the first step in the JA biosynthesis pathway (Schommer et al. 2008). TCP4 was consistently repressed in the JPN1-infected samples throughout the infection. However, only slight changes could be observed in the UK1-infected samples. A similar but less pronounced repression was observed for LOX2 in the JPN1 group. In contrast to the results of TCP4, LOX2 was overaccumulated at 16 DPI in the UK1 group (Fig. $5 \mathrm{C})$. Because JA signaling is usually antagonistic to SA signal- ing and SA signaling is important for plant defense against virus, these results encouraged us to further investigate the effect of these hormones on ORE1- and ORS1-dependent genes analyzed.

\section{SA and methyl jasmonate (MeJA) effects \\ on ORE1 and ORS1 senescence networks.}

Our results revealed that several SAG were induced by UK1 at 4 DPI in leaf 11 soon after its emergence (Figs. 5A and 3A). These findings, together with the reported role of SA and JA both in modulating senescence and orchestrating plant defense (Guo and Gan 2005; Quirino et al. 2000), led us to investigate the expression profile of the analyzed SAG in response to these hormones (Fig. 6A; Supplementary Table S2). In agreement with previous reports (Besseau et al. 2012), WRKY70 showed a strong response to SA after $4 \mathrm{~h}$ and was induced by MeJA, though to a much lesser extent. None of these hormones altered mature miR164 accumulation. Most of the genes analyzed of the ORE1 and ORS1 regulons were upregulated by SA, including ORE1 itself. By contrast, three genes were downregulated by MeJA treatment, and no analyzed gene was found to be induced by this hormone. In contrast with ORE1, however, ORS1 did not change upon SA treatment. A
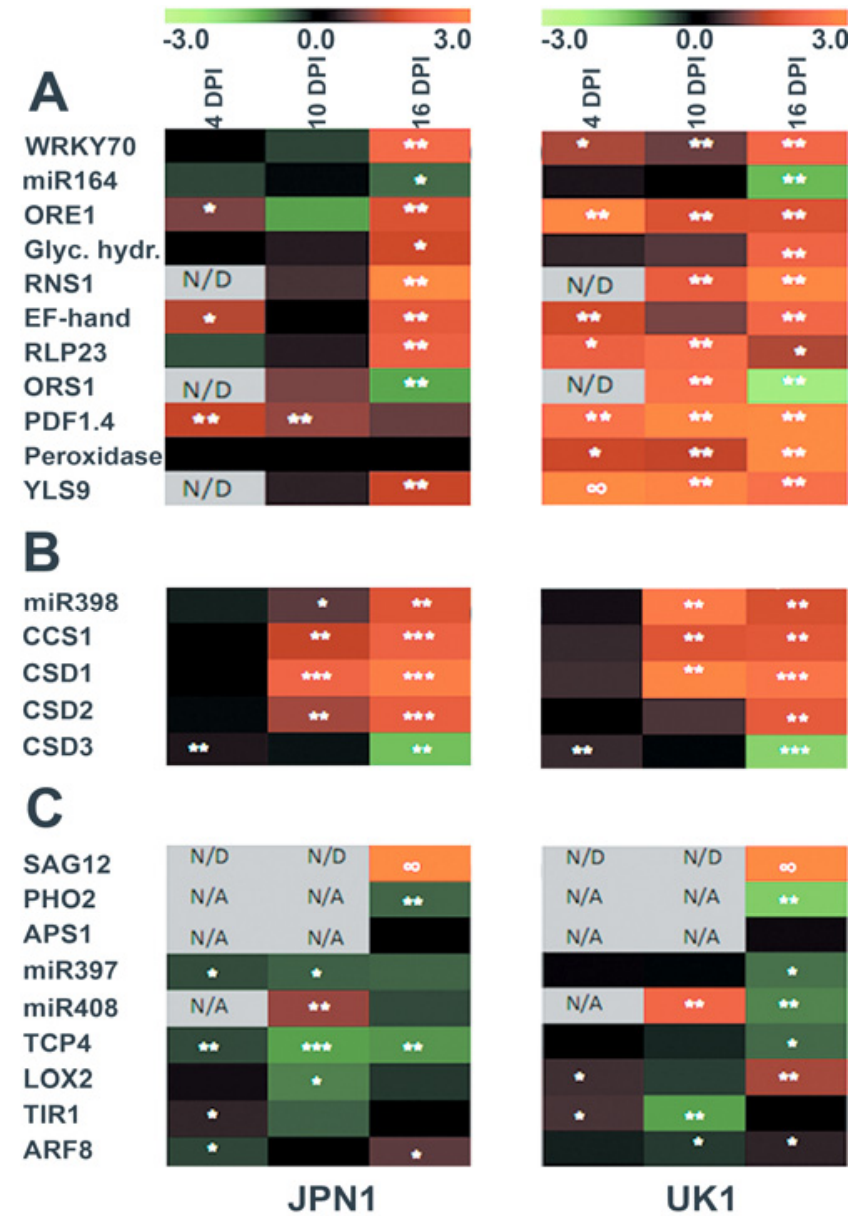

Fig. 5. Quantitative reverse-transcription polymerase chain reaction (qRTPCR) analysis of selected genes upon infection by Turnip mosaic virus (TuMV) strains. Heat maps illustrating qRT-PCR results are shown for $\mathbf{A}$, senescence-associated genes; $\mathbf{B}$, copper-zinc superoxide dismutase $\left(\mathrm{O}_{2}^{-}\right)$ scavenging system; and $\mathbf{C}$, other relevant genes related to nutrient stress, hormone response, and senescence. Comparisons were made between mocktreated samples and JPN1 or UK1, as indicated. Log2 fold change values are given in a double-color scale. N/A = not analyzed, N/D = not detected, and $\infty=$ detected only in virus-infected samples; $*=0.01 \leq P \leq 0.05$, ** $=$ $0.001 \leq P \leq 0.01$, and $* * *=P \leq 0.001$. 
possible explanation for this might be different timings of induction between these closely related paralogs under the same stimulus, as previously reported (Balazadeh et al. 2011). Thus, we analyzed both SAG $24 \mathrm{~h}$ after induction. ORE1 showed a sustained increase after SA application but ORS1 remained unchanged (Fig. 6B). MeJA exhibited a late effect on ORE1, accentuating the tendency toward its downregulation shown at $4 \mathrm{~h}$. No effect was detected on ORS1.

Differential senescence progression and $\mathrm{H}_{2} \mathrm{O}_{2}$ accumulation between strains are lost in SA-defective NahG plants.

Several transcripts belonging to SAG and some of them coding for ROS-generating enzymes are early overaccumulated in

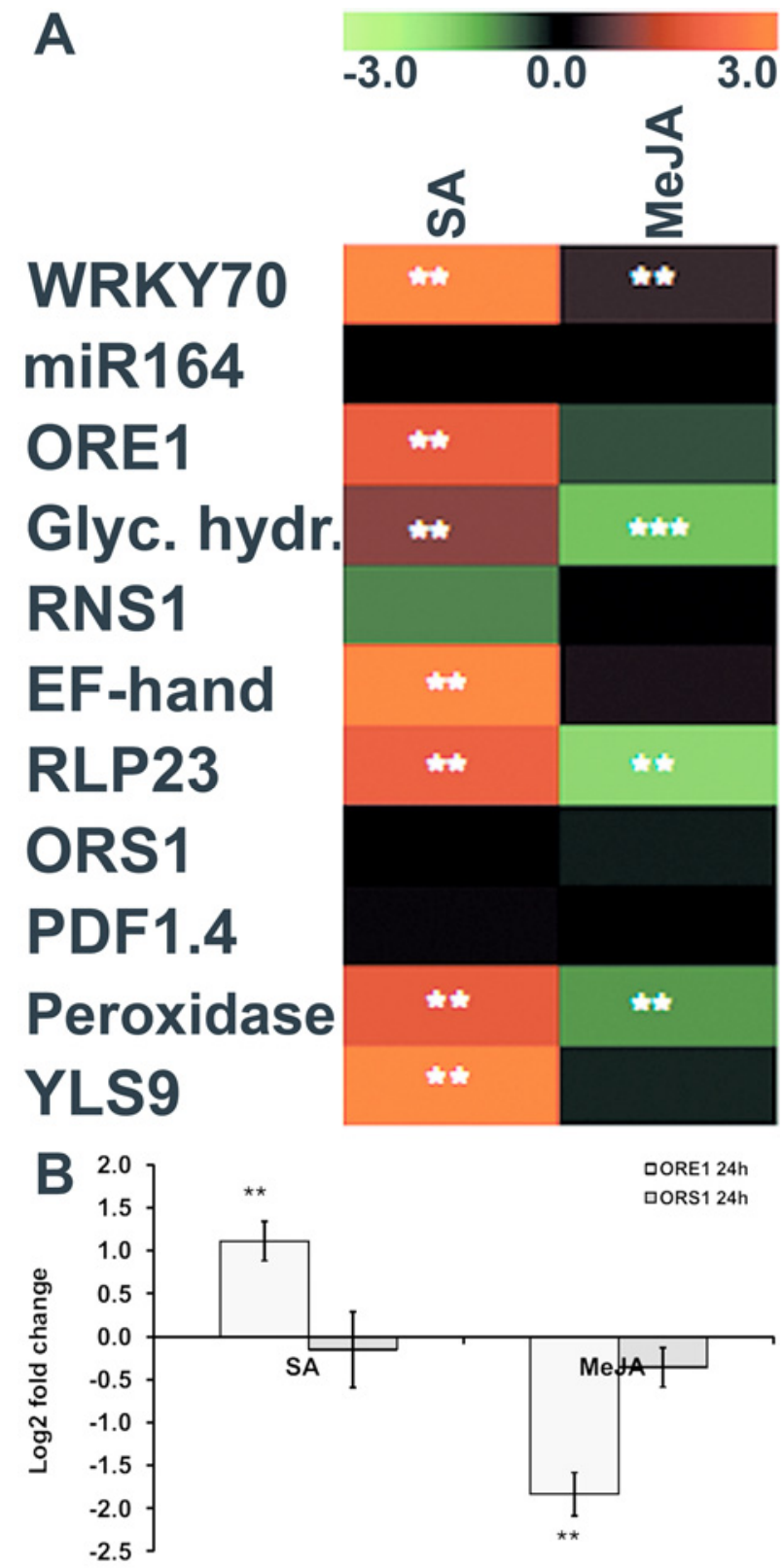

Fig. 6. Quantitative reverse-transcription polymerase chain reaction analysis of selected senescence-associated genes (SAGs) upon application of salicylic acid (SA) and methyl jasmonate (MeJA). A, SAGs and other relevant genes tested after $4 \mathrm{~h}$ of hormone treatments. Log 2 fold change values are given in a double-color scale. B, ORE1 and ORS1 were analyzed $24 \mathrm{~h}$ post-treatment. Comparisons were made between mock-treated samples and SA or MeJA, as indicated. Error bars represent standard error; ** = $0.001 \leq P \leq 0.01$ and $* * *=P \leq 0.001$.
UK1- but not JPN1-infected plants (Fig. 5A) and most of them were found to be SA responsive (Fig. 6). Thus, we hypothesized that differential SA responses could be underlying the distinct senescence phenotypes associated with both TuMV strains. To investigate this possibility, we used NahG-transgenic plants, which have impaired SA accumulation, and repeated measurements of senescence parameters and ROS accumulation during viral infections with JPN1 and UK1 TuMV strains. The set of senescence parameters analyzed is shown in Figure 7. NahG plants presented delayed developmental senescence compared with ColO plants (Figs. 2 and 7, mock-inoculated controls), a phenotype previously described (Buchanan-Wollaston et al. 2005). Interestingly, almost all differences between mock- and virus-inoculated plants were lost (Fig. 7A to D), with the exception of anthocyanin accumulation (Fig. 7E). None of the physiological markers of senescence presented statistically significant differences between strains. Similarly to Col0, however, UK1 infections triggered growth arrest phenotypes in NahG plants, as revealed by the growth rate of leaf 11. Nevertheless, differently from Col0 plants, JPN1 also induced growth arrest beyond 11 DPI in NahG plants (Table 2; Supplementary Fig. S4). ROS accumulation was measured in leaf 11 of NahG plants (Fig. 8). DAB staining showed no differences in $\mathrm{H}_{2} \mathrm{O}_{2}$ levels between treatments during the experiment (Fig. 8A). However, $\mathrm{O}_{2}^{-}$overaccumulated in UK1-infected NahG plants and JPN1 induced a transient overaccumulation of this ROS at 16 DPI, as shown by NBT staining (Fig. 8B).

\section{DISCUSSION}

\section{UK1 triggers earlier senescence and} more severe symptoms than JPN1 despite accumulating similar viral RNA levels.

In this study, we used two closely related TuMV strains (UK1 and JPN1) to investigate the bases of their contrasting symptom induction. This allowed us to associate phenotypes with the differential ROS accumulation, antioxidant responses, and distinct expression of SAG. A previous report had compared the transcriptomic effects of infections of two Potato virus $Y$ (PVY) strains with differential accumulation level on potato plants and showed several differentially regulated antioxidant-related genes at early time points after infection using inoculated leaves for analysis (Kogovsek et al. 2010). On the other hand, in the present study, all measurements were done in systemically infected leaves. Phenotype recording showed differential symptomatology triggered by both strains despite accumulating similar levels of viral RNA (Fig. 1). A similar scenario has been recently described for a potexvirus, Pepino mosaic virus, infecting tomato (Hanssen et al. 2011). Among differential symptomatology triggered by both strains, rosette yellowing was notably accelerated in UK1-infected plants (Fig. 1A). UK1 clearly accelerated senescence in comparison with JPN1 in Col0 plants (Fig. 2). On the other hand, viruses failed to accelerate senescence in NahG plants (Fig. 7). The analysis of antioxidant content showed evident differences between strains in Col0 plants (Fig. 2D to F). These compounds change their accumulation in a senescence-driven manner but also play important roles in oxidative protection (Breeze et al. 2011; Gould 2004; Nagata et al. 2003).

\section{Accumulation of UK1-induced antioxidant molecules and} ROS depend on SA and correlate with symptom severity.

ROS production is a common outcome of viral infections and plants that cannot cope with excessive $\mathrm{O}_{2}{ }^{-}$accumulation fail to flower and have impaired vegetative growth (Nagata et al. 2003). Accordingly, UK1 (but not JPN1) induced the arrest of the growth of flowers (Fig. 1A) and systemic leaves (Fig. 3; 
Table 1). Analysis of $\mathrm{H}_{2} \mathrm{O}_{2}$ and $\mathrm{O}_{2}^{-}$levels (Fig. 4) revealed differential ROS accumulation induced by these strains: whereas JPN1 remained indistinguishable from mock levels throughout the experiment, UK1 overaccumulated both types of ROS. Further, in NahG plants, the growth arrest phenotype induced by UK1 was associated with increased $\mathrm{O}_{2}^{-}$levels (Fig. 8B; Table 2) though no $\mathrm{H}_{2} \mathrm{O}_{2}$ overaccumulation could be detected (Fig. 8A). The growth arrest detected in JPN1 between 11 and 21 DPI in NahG plants also correlated with a transient overaccumulation of $\mathrm{O}_{2}^{-}$at $16 \mathrm{DPI}$. Together, these findings suggest $\mathrm{O}_{2}^{-}$as the main ROS responsible for growth arrest phenotypes; however, more experiments are needed to further clarify this point. Therefore, a scenario arises in which UK1 triggers an overaccumulation of ROS (both the SA-dependent $\mathrm{H}_{2} \mathrm{O}_{2}$ and the SA-independent $\mathrm{O}_{2}^{-}$) that, in turn, provokes impaired cellular functions, leading to growth arrest and early senescence in Col0 plants. JPN1 also induced senescence but in a milder way, suggesting that other mechanisms distinct from ROS damage or signaling are involved. Normal SA levels and concomitant $\mathrm{H}_{2} \mathrm{O}_{2}$ accumulation during the infections are needed for differential senescence progression observed between strains. Anthocyanins were differently accumulated between mock- and virus-infected NahG plants but differences between strains were abolished (Fig. 7E). Anthocyanins were found to be several-fold overaccumulated throughout the experiment in $\mathrm{NahG}$ when compared with Col0 plants following mock inoculations (Figs. 2D and 7E, solid lines). This finding

Table 2. Intra-treatments statistic analysis of NahG leaf 11 area growth at 4 to 21 days postinoculation (DPI) ${ }^{\mathrm{a}}$

\begin{tabular}{lccc}
\hline Column 1 & Mock & JPN1 & UK1 \\
\hline 4 DPI vs. 11 DPI & $*$ & $* *$ & $* * *$ \\
4 DPI vs. 16 DPI & $* * *$ & $* * *$ & $* * *$ \\
4 DPI vs. 21 DPI & $* * *$ & $* * *$ & $* * *$ \\
11 DPI vs. 16 DPI & $\mathrm{Ns}$ & $\mathrm{ns}$ & $\mathrm{ns}$ \\
11 DPI vs. 21 DPI & $*$ & $\mathrm{~ns}$ & $\mathrm{~ns}$ \\
16 DPI vs. 21 DPI & $\mathrm{Ns}$ & $\mathrm{ns}$ & $\mathrm{ns}$ \\
\hline
\end{tabular}

a $12 \leq n \leq 18$ for each treatment and time point; $\mathrm{ns}=$ no significant statistical differences between the time points compared within a given treatment.
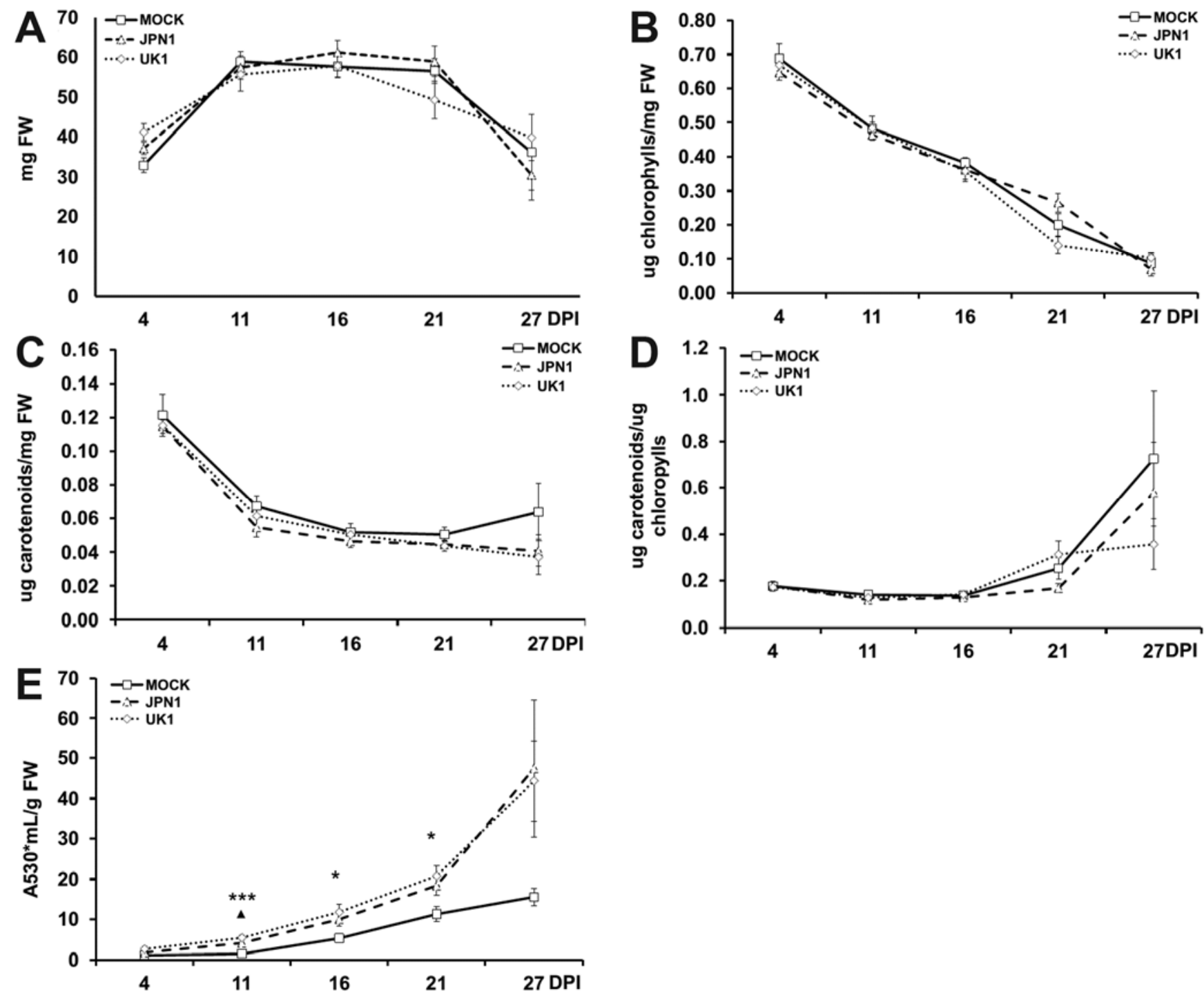

Fig. 7. Comparative senescence parameters in Turnip mosaic virus (TuMV)-infected NahG plants. Fifth leaves were harvested from plants inoculated with buffer only (mock) or JPN1 or UK1 TuMV strains at 4 to 27 days postinoculation (DPI). A, Fresh weight measurements of the sampled leaves during the experiment; $10 \leq n \leq 23$ leaves per treatment and DPI. B, Total chlorophylls; $\mathbf{C}$, carotenoids; $\mathbf{D}$, carotenoid/chlorophyll ratio; and $\mathbf{E}$, anthocyanins content in leaf 5 of mock- and virus-inoculated plants across the experiment; $4 \leq n \leq 9$ leaves per treatment and DPI. Asterisks and small triangles indicate significant differences between mock/UK1- and mock/JPN1-inoculated samples, respectively. One-way analysis of variance with Tukey's post-test was performed. Error bars represent standard error. 
is in line with previously reported milder symptoms developed by NahG plants under several RNA virus infections and could be attributed to their higher content of reduced antioxidants, which also attenuated viral symptoms when applied exogenously (Wang et al. 2011). Similarly, we observed no $\mathrm{H}_{2} \mathrm{O}_{2}$ overaccumulation in UK1-infected NahG plants (Fig. 8A), a result also previously reported (Wang et al. 2011). This scenario might be plausible because the initial oxidative burst after pathogen infection is followed by SA biosynthesis which, in turn, affects the ROS levels in a positive feedback loop (Yuan and Lin 2008).

Moreover, whereas, in Col0 plants, $\mathrm{O}_{2}^{-}$levels increased between 70 and $180 \%$ during the experiment in UK1-infected plants relative to mock-inoculated controls, UK1-infected NahG plants overaccumulated only 50 to $80 \%$ (Figs. 4B and 8B).

\section{ROS-generating and -scavenging systems}

\section{are both differentially regulated by JPN1 and UK1.}

Differential ROS accumulation could result from alterations in ROS production or scavenging systems. qPCR analysis revealed that both strains regulated differently key genes implicated in these processes in Col0 plants (Fig. 5). Although JPN1 and UK1 seems to both be recognized by the plant, considering the early induction of PDF1.4, a SA-insensitive defensinlike protein (Fig. 6A), only UK1 upregulated ROS-generating
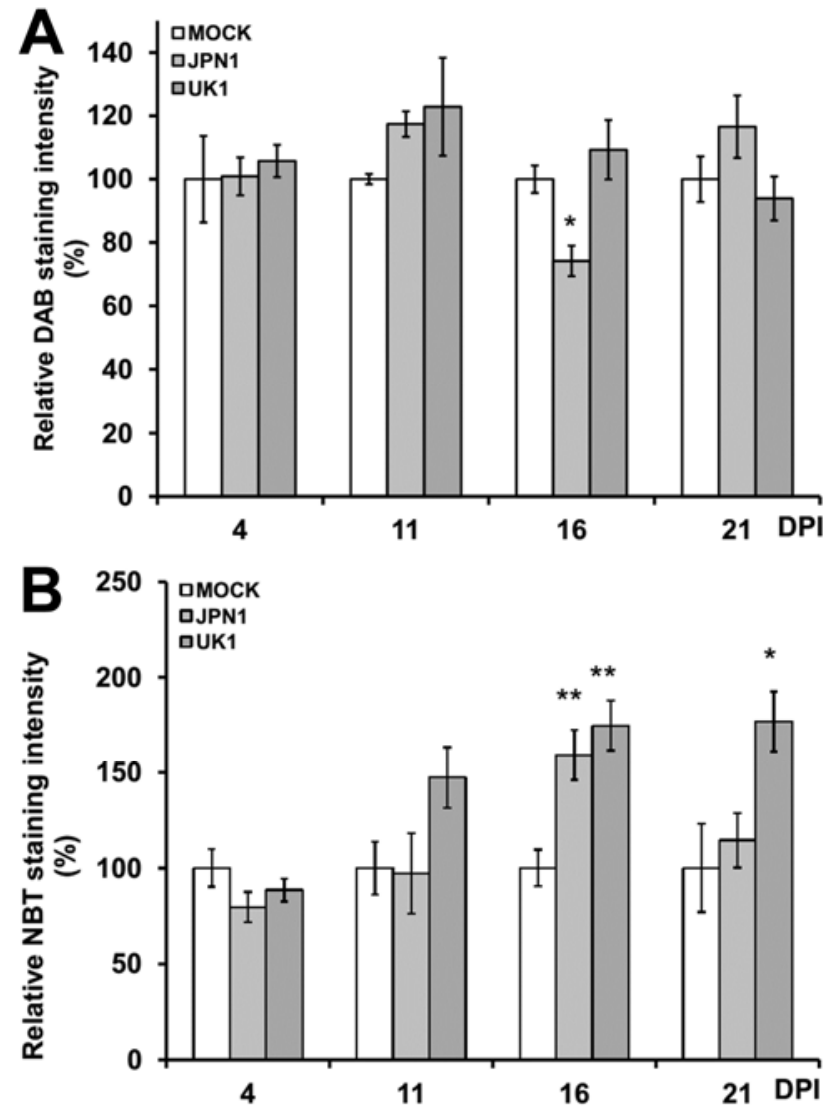

Fig. 8. UK1-induced reactive oxygen species accumulation is partially abolished in NahG plants. A, Relative quantification of 3,3-diaminobenzidine staining on 11th leaves. Individual intensity values were normalized to mock-inoculated controls at each day postinoculation (DPI) analyzed. Mean values were calculated for mock-inoculated controls (white bars) and JPN1- and UK1-infected samples (light and dark gray bars, respectively). B, Same as in A for quantification of nitro blue tetrazolium chloride staining; $4 \leq n \leq 6$ leaves per treatment and DPI. One-way analysis of variance with Tukey's post-test were performed. Error bars represent standard error. peroxidase starting from 4 DPI (Fig. 5A). Consistently, ROS accumulation peaks at 16 DPI in UK1-infected samples (Fig. 4), coinciding with a maximum in peroxidase upregulation. Though other enzymes such as NADPH oxidases are also important to ROS generation (Torres 2010), our analysis identified a differential regulation between strains in a key ROSgenerating and pathogen-responsive peroxidase. This result is important because it allows us to link phenotypic observations with a putative molecular model for the differential ROS accumulation between strains, though deeper studies are needed to confirm this association.

LOXs are activated during the senescence (Lynch and Thompson 1984) and LOX2 is a chloroplastic enzyme that produces ROS (Bell et al. 1995). Only UK1 induced upregulation of LOX2 at 16 DPI (Fig. 5C). The sustained downregulation of TCP4 induced by JPN1 could explain this difference, because TCP4 controls LOX2 expression (Schommer et al. 2008).

The detoxification mechanisms of the cell were assessed by analyzing the $\mathrm{O}_{2}^{-}$scavenging system composed by the cytoplasmic CSD1, the chloroplastic CSD2, and their chaperone CCS1, together with their negative regulator miR398 (Fig. 5B). Although similar patterns were seen between strains, a remarkable exception was seen at $10 \mathrm{DPI}$, when CSD2 was strongly upregulated in JPN1-infected plants but no significant differences were detected in UK1-infected plants. This difference coincided with a higher expression of miR398 in UK1infected samples by 10 DPI that could be preventing CSD2 overaccumulation. Because chloroplasts are a main source of ROS (Asada 2006; Bhattacharjee 2012) and chloroplastic CSD2 is not upregulated in UK1-infected plants until 16 DPI, it could be suggested that the $\mathrm{O}_{2}^{-}$scavenging system is impaired in these plants.

The overaccumulation of miR398 under late viral infections was unexpected because miR398 is predicted to be downregulated by ROS and biotic stresses (Jagadeeswaran et al. 2009). MiR398 is induced under copper deprivation (Yamasaki et al. 2007). We analyzed the accumulation profile of miR397 and mIR408, which are also upregulated under copper deficiency, through their common activation via the SPL7 TF (Yamasaki et al. 2009). No clear upregulation pattern was detected for these miRNAs (Fig. 5C). Therefore, copper deprivation is unlikely to be the driving force behind miR398 overaccumulation.

Together, the sustained and strong upregulation of the ROSgenerating Peroxidase 71 and the late upregulation of LOX2 observed only in UK1-infected plants (Fig. 5A and C) and the differential accumulation profile of CSD2 (Fig. 5B) are consistent with the contrasting ROS accumulation observed between strains (Fig. 4). Thus, both ROS generation and scavenging systems are differently altered by UK1 and JPN1.

\section{Transcriptomic analysis reveals early UK1-induced SAG overaccumulation and late convergence between both TuMV strains.}

Notable differences between JPN1- and UK1-induced gene expression changes were detected when ORE1 and ORS1 regulons were analyzed. (Fig. 5A). Remarkably, UK1 upregulated many SAG at 4 DPI, when leaf 11 had barely emerged (Fig. 3A). Sustained ROS overaccumulation in systemic UK1infected young leaves was associated with early induction of many SAG that could, in turn, lead to an irreversible triggering of full senescence. These findings are consistent with a study that demonstrated extensive overlap between senescence and pathogen-induced TF (Chen et al. 2002). Differences between strains were found again at 10 DPI, when no visible leaf yellowing could as yet be detected (Fig. 3A). However, a tendency to converge was found for both virus-induced $\mathrm{SAG}$ profiles at 
16 DPI. This situation is in agreement with a recent report showing that, at later stages, senescence networks triggered by diverse stimuli converged (Guo and Gan 2012).

ORE1 is induced at 4 and 10 DPI under UK1 infection when no downregulation of its negative regulator miR164 was detected. At 16 DPI, however, miR164 and ORE1 accumulation were negatively correlated following both viral treatments, suggesting transcriptional regulation of ORE1 at early stages of infection but an additional effect of senescence-driven posttranscriptional regulation at $16 \mathrm{DPI}$.

The strong downregulation of its paralog ORS1 at 16 DPI was unexpected because not only is ORS1 greatly induced by $\mathrm{H}_{2} \mathrm{O}_{2}$, a metabolite accumulated in UK1-infected leaves, but both paralogs also possess high promoter sequence conservation and play similar roles in promoting senescence (Balazadeh et al. 2011). Interestingly, both strains induced similar changes on the accumulation profile of these master regulators of senescence in $B$. juncea. This emphasizes not only the conserved response of both paralogs to a common stress in Brassicaceae spp. but also the differential responses between them to an external stimulus.

\section{$\mathrm{SA}$ and $\mathrm{H}_{2} \mathrm{O}_{2}$ interplay is a key component of differential senescence responses.}

Senescence is delayed considerably in NahG plants where several SAG belonging to ORE1 and ORS1 regulons are highly downregulated compared with wild-type plants (BuchananWollaston et al. 2005). ORE1 and ORS1 themselves are also upregulated by $\mathrm{H}_{2} \mathrm{O}_{2}$ (Balazadeh et al. 2011). Therefore, NahG plants have seriously impaired the signaling of these senescence networks through both the lack of accumulation of SA (to which ORE1 and other SAG respond) and $\mathrm{H}_{2} \mathrm{O}_{2}$ (to which both NAC paralogs responds). In this regard, the loss of senescence acceleration in NahG-infected plants could be attributed, at least in part, to the break in the $\mathrm{SA}-\mathrm{H}_{2} \mathrm{O}_{2}$ feedback system. Interestingly, a recent study using the potyvirus $\mathrm{PVY}^{\mathrm{NTN}}$ has shown that $\mathrm{SA}$ is essential in determining the development of disease symptoms and early transcriptomic changes in compatible interactions with a tolerant cultivar of potato (Baebler et al. 2011). Our findings underline a central role of SA in determining senescence progression following different TuMV strain infections. Also in potato, SA levels were increased in a susceptible cultivar after infection with PVY ${ }^{\mathrm{NTN}}$, even in systemic leaves at $1 \mathrm{dpi}$ (Krecic-Stres et al. 2005). Nonetheless, it was found that mutant plants impaired in SA pathway were not more susceptible than Col0 plants to infection, contrasting to what was observed following infection with cellular pathogens (Huang et al. 2005). Similar results were obtained in a work that described milder symptoms in NahG plants after infections with different RNA viruses, despite the lower overaccumulation of key SA-responsive defense genes (Wang et al. 2011). Based on our results, we speculate that disturbed ORE1 or ORS1 senescence networks could be playing a central role in determining milder symptoms after viral infections on SA-defective plants.

\section{The outcome of TuMV infection involves intricate networks, including differential $\mathrm{SA}$ response and competition for nutrients.}

Whereas it has been proposed that leaf phenotypes induced by TuMV infection are mainly due to the misregulation of ARF8 (Jay et al. 2011), our results (Fig. 5C) are more in agreement with a previous work that did not find changes in ARF8 accumulation in either inoculated or systemically infected leaves; our data are also in agreement with the upregulation of CSD1 and CSD2 showed in this work (Yang et al. 2007).

Nevertheless, caution must be adopted when comparing different approaches in the study of viral infections. Infected leaves comprise a heterogeneous mixture of host responses (Maule et al. 2002). Consequently, direct comparisons between inoculated and systemically infected leaves should be carefully interpreted.

Taken together, our results indicate that both strains induce senescence and produce symptoms through partially different pathways. Nutrient deprivation is a common outcome of both viral infections, as shown here by $\mathrm{PHO} 2$ downregulation at 16 DPI, consistent with the reported amino acid level depletion at late stages of viral infection (Bazzini et al. 2011). Anthocyanin rise observed in virus-infected plants could be also a response to nitrogen and phosphorous depletion (Kant et al. 2011; Peng et al. 2007, 2008). Because viral accumulation reached similar levels for both strains (Fig. 1B), simple resource competition fails to explain the differential symptoms. However, the senescence process in JPN1-treated plants could be a partial consequence of this deprivation. In UK1-infected plants, this process would be further exacerbated via the ROS overaccumulation produced by SA-dependent ROS-generating enzymes and early activation of ORE1 and ORS1 regulons.

Several lines of evidence point to SA as the key hormone responsible for the main differences in symptoms observed between strains. The extensive overlapping between early response to UK1 and the SA response of many SAG, the partial abolition of symptoms differences, and ROS accumulation between strains in NahG plants are strong evidence supporting this hypothesis. Additional investigation needs to be done in order to unravel the mechanism inducing symptom differences between both TuMV strains. Nevertheless, a possibility begins to develop integrating our data with recently published work (Conti et al. 2012; Love et al. 2012). In line with these recent findings, it is tempting to envision a viral suppressor factor of SA-mediated response that could be active in JPN1 but not in UK1, completely changing SA-mediated response as observed here, and affecting symptom production but not virus accumulation.

\section{MATERIALS AND METHODS}

\section{Plant growth conditions.}

Seed were stratified at $4^{\circ} \mathrm{C}$ for 3 days. A. thaliana Col- 0 and $\mathrm{NahG}$ plants were grown under standard conditions (Boyes et al. 2001) in controlled environmental chamber. B. juncea plants were maintained in greenhouse with a photoperiod of 16 and $8 \mathrm{~h}$ and temperature of 22 to $25^{\circ} \mathrm{C}$ (day) and $20^{\circ} \mathrm{C}$ (night), respectively.

\section{Virus infection assays.}

TuMV-UK1 (accession number X65978), TuMV-JPN1, and TuMV-GFP strains were maintained in infected $A$. thaliana Col-0. Fresh sap was obtained immediately prior to use to inoculate plants. Mock-inoculated plants were rubbed with sodium sulfite buffer $\left(1 \% \mathrm{~K}_{2} \mathrm{HPO}_{4}+0,1 \% \mathrm{Na}_{2} \mathrm{SO}_{3}\right.$ [wt/vol] $)$. Plants were mechanically inoculated in their third true leaf at stage 1.08 (Boyes et al. 2001), because those leaves were almost fully developed by the time of the procedure.

\section{Pigment measurements.}

Pigments were extracted from individual samples of leaf 5. Chlorophylls and carotenoids were extracted using $96 \%$ ethanol. Anthocyanins were extracted with methanol/ $\mathrm{HCl}$ (99:1 [vol/vol]) and quantified as described by Rabino and Mancinelli (1986), with modifications. All pigment extracts were stored at room temperature for $16 \mathrm{~h}$ in the dark with gentle agitation. Absorbance of $0.2 \mathrm{ml}$ was measured at 664, 649, and 470nm (chlorophylls and carotenoids) or 530 and $657 \mathrm{~nm}$ (anthocyanins) in a Multiskan Spectrum (Thermo Fisher Corp., Waltham, MA, U.S.A.). Chlorophyll concentrations were calculated using the following equations: $C_{a+b}=$ total chlorophylls $(\mu \mathrm{g} / \mathrm{ml})=$ 
$22.24 \times \mathrm{A}_{649}+5.24 \times \mathrm{A}_{664}, \mathrm{C}_{\mathrm{a}}=$ chlorophyll a $(\mu \mathrm{g} / \mathrm{ml})=13.36 \times$ $\mathrm{A}_{664}-5.19 \times \mathrm{A}_{649}$, and $\mathrm{C}_{\mathrm{b}}=$ chlorophyll $\mathrm{b}(\mu \mathrm{g} / \mathrm{ml})=27.43 \times$ $\mathrm{A}_{649}-8.12 \times \mathrm{A}_{664}$. Carotenoid concentrations were calculated using $\mathrm{C}_{\mathrm{c}}=$ total carotenoids $(\mu \mathrm{g} / \mathrm{ml})=\left(1,000 \times \mathrm{A}_{470}-2.13 \times\right.$ $\left.\mathrm{C}_{\mathrm{a}}-97.64 \times \mathrm{C}_{\mathrm{a}}\right) / 209$. Anthocyanin contents were calculated using $\mathrm{A}_{530}-0.25 \times \mathrm{A}_{657}$.

\section{DAB staining and quantification.}

DAB treatment was adapted from Thordal-Christensen and associates (1997). At 4, 11, 16, and 21 DPI, the 11th leaves of the plants was excised at the petiole with chirurgical scissors, immersed in DAB (Sigma-Aldrich, St. Louis) solution, and kept overnight in the dark under gentle agitation. Reactions were stopped and leaves were ethanol clarified. To quantify the level of DAB staining, samples were scanned using Image Scanner (GE Healthcare, Piscataway, NJ. U.S.A.). Densities were assessed using image analysis software (ImageJ for Windows, v1.46p). Background was calculated by immersing leaves in a solution without $\mathrm{DAB}$, ethanol clarifying as described above, scanning at the same time, and subtracting the mean value of three replicates to each of the DAB-treated leaves. Averages were calculated after data normalization to mocktreated plants.

\section{NBT staining and quantification.}

For NBT staining, 11th leaves were sampled as for DAB treatment. Leaves were submerged in an NBT solution (Invitrogen, Molecular Probes, Eugene, OR, U.S.A.) as previously described (Wohlgemuth et al. 2002). Solutions were infiltrated into leaf tissues by 2-min vacuum shocks in a vacuum chamber; then, the infiltrated leaf tissues were incubated for $2 \mathrm{~h}$ in the dark under gentle agitation. Ethanol clarifying, image analysis, and background subtraction were performed as described for DAB treatment.

\section{Leaf area calculations.}

Data from 11th leaves scanned for quantification of DAB and NBT staining were used to compare tissue growth using ImageJ software.

\section{Hormone treatments.}

SA or MeJA at $0.5 \mathrm{mM}$ were sprayed on Col0 plants at growth stage 1.08. Effectiveness of treatments was confirmed by qRT-PCR using MeJA-inducible LOX2 (AT3G45140) (Bell and Mullet 1993) and SA-inducible PR1 (AT2G14610) (Uknes et al. 1992) (Supplementary Fig. S3).

\section{Oligonucleotide primer sets and real-time qPCR.}

Oligonucleotide primer sets for real-time qPCR were designed using Vector NTI Advance 9 software (Life Technologies, Carlsbad, CA, U.S.A.). They are listed in Supplementary Table S3. MicroRNA primers for cDNA synthesis and qPCR assays were adapted from (Chen et al. 2005).

Details on the minimum information for publication of quantitative real-time PCR experiments requirements are listed in Supplementary Tables S4 and Table S5.

\section{Statistical analysis.}

One-way analysis of variance with Tukey's post-test and Kruskal-Wallis test with Dunn's post-test were performed using GraphPad Prism (version 5.03 for Windows; GraphPad Software, San Diego, CA, U.S.A.). For all statistical analysis, significance was set as $* / \Delta=0.01 \leq P \leq 0.05, * * / \Delta \Delta=0.001 \leq$ $P \leq 0.01$, and $* * * / \Delta \Delta \Delta=P \leq 0.001$ throughout the experiments. For qPCR analysis, LingRegPCR program (Ramakers et al. 2003) and the normalization method of Pfaffl and associates (2002) were used. Relative expression ratios and statistical analysis were performed using fgStatistics software interface (version 2009; Córdoba, Argentina). A false-discovery rate adjustment was applied for correcting for multiple comparisons (Benjamini and Hochberg 1995) using a threshold of 0.05 .

\section{ACKNOWLEDGMENTS}

This work was supported by the Instituto Nacional de Tecnología Agropecuaria (INTA) (PE 243532 to S. Asurmendi). The collaboration Spain-Argentina was supported by the binationally funded Integrated Action (AR2009-0022) (Spain) and MINCyT/MICINN (ES/09/03) (Argentina). Work in Spain was partially funded by grants (RTA2007-00052 to F. Sánchez and RTA2010-00098 to F. Ponz). D. Zavallo hold a fellowship from CONICET and C. A. Manacorda from INTA. We thank J. Sabio y García for assistance with English-language editing.

\section{LITERATURE CITED}

Abdel-Ghany, S. E., and Pilon, M. 2008. MicroRNA-mediated systemic down-regulation of copper protein expression in response to low copper availability in Arabidopsis. J. Biol. Chem. 283:15932-15945.

Archetti, M., Doring, T. F., Hagen, S. B., Hughes, N. M., Leather, S. R. Lee, D. W., Lev-Yadun, S., Manetas, Y., Ougham, H. J., Schaberg, P. G., and Thomas, H. 2009. Unravelling the evolution of autumn colours: An interdisciplinary approach. Trends Ecol. Evol. 24:166-173.

Asada, K. 2006. Production and scavenging of reactive oxygen species in chloroplasts and their functions. Plant Physiol. 141:391-396.

Ascencio-Ibanez, J. T., Sozzani, R., Lee, T. J., Chu, T. M., Wolfinger, R. D., Cella, R., and Hanley-Bowdoin, L. 2008. Global analysis of Arabidopsis gene expression uncovers a complex array of changes impacting pathogen response and cell cycle during geminivirus infection. Plant Physiol. 148:436-454.

Baebler, S., Stare, K., Kovac, M., Blejec, A., Prezelj, N., Stare, T., Kogovsek, P., Pompe-Novak, M., Rosahl, S., Ravnikar, M., and Gruden, K. 2011. Dynamics of responses in compatible potato-Potato virus $Y$ interaction are modulated by salicylic acid. PLoS One 6:e29009. Published online.

Balazadeh, S., Riano-Pachon, D. M., and Mueller-Roeber, B. 2008. Transcription factors regulating leaf senescence in Arabidopsis thaliana. Plant Biol. (Stuttg.) 10 (Suppl. 1):63-75.

Balazadeh, S., Siddiqui, H., Allu, A. D., Matallana-Ramirez, L. P., Caldana, C., Mehrnia, M., Zanor, M. I., Kohler, B., and Mueller-Roeber, B. 2010a. A gene regulatory network controlled by the NAC transcription factor ANAC092/AtNAC2/ORE1 during salt-promoted senescence. Plant J. 62:250-264.

Balazadeh, S., Wu, A., and Mueller-Roeber, B. 2010b. Salt-triggered expression of the ANAC092-dependent senescence regulon in Arabidopsis thaliana. Plant Signal. Behav. 5:733-735.

Balazadeh, S., Kwasniewski, M., Caldana, C., Mehrnia, M., Zanor, M. I., Xue, G. P., and Mueller-Roeber, B. 2011. ORS1, an H(2)O(2)-responsive NAC transcription factor, controls senescence in Arabidopsis thaliana. Mol. Plant 4:346-360.

Bazzini, A. A., Manacorda, C. A., Tohge, T., Conti, G., Rodriguez, M. C., Nunes-Nesi, A., Villanueva, S., Fernie, A. R., Carrari, F., and Asurmendi, S. 2011. Metabolic and miRNA profiling of TMV infected plants reveals biphasic temporal changes. PLoS One 6:e28466. Published online.

Beauclair, L., Yu, A., and Bouche, N. 2010. microRNA-directed cleavage and translational repression of the copper chaperone for superoxide dismutase mRNA in Arabidopsis. Plant J. 62:454-462.

Bell, E., and Mullet, J. E. 1993. Characterization of an Arabidopsis lipoxygenase gene responsive to methyl jasmonate and wounding. Plant Physiol. 103:1133-1137.

Bell, E., Creelman, R. A., and Mullet, J. E. 1995. A chloroplast lipoxygenase is required for wound-induced jasmonic acid accumulation in Arabidopsis. Proc. Natl. Acad. Sci. U.S.A. 92:8675-8679.

Benjamini, Y., and Hochberg, Y. 1995. Controlling the false discovery rate: A practical and powerful approach to multiple testing. J. R. Stat. Soc. Ser. B (Methodol.) 57:289-300.

Besseau, S., Li, J., and Palva, E. T. 2012. WRKY54 and WRKY70 cooperate as negative regulators of leaf senescence in Arabidopsis thaliana. J. Exp. Bot. 63:2667-2679.

Bhattacharjee, S. 2012. The language of reactive oxygen species signaling in plants. J. Bot. 2012:1-22.

Bindschedler, L. V., Dewdney, J., Blee, K. A., Stone, J. M., Asai, T., Plotnikov, J., Denoux, C., Hayes, T., Gerrish, C., Davies, D. R., Ausubel, F. M., and Bolwell, G. P. 2006. Peroxidase-dependent apoplastic oxidat- 
ive burst in Arabidopsis required for pathogen resistance. Plant J. 47:851-863

Boyes, D. C., Zayed, A. M., Ascenzi, R., McCaskill, A. J., Hoffman, N. E. Davis, K. R., and Gorlach, J. 2001. Growth stage-based phenotypic analysis of Arabidopsis: A model for high throughput functional genomics in plants. Plant Cell 13:1499-1510.

Breeze, E., Harrison, E., McHattie, S., Hughes, L., Hickman, R., Hill, C. Kiddle, S., Kim, Y. S., Penfold, C. A., Jenkins, D., Zhang, C., Morris, K., Jenner, C., Jackson, S., Thomas, B., Tabrett, A., Legaie, R., Moore, J. D., Wild, D. L., Ott, S., Rand, D., Beynon, J., Denby, K., Mead, A., and Buchanan-Wollaston, V. 2011. High-resolution temporal profiling of transcripts during Arabidopsis leaf senescence reveals a distinct chronology of processes and regulation. Plant Cell 23:873-894.

Buchanan-Wollaston, V. 1997. The molecular biology of leaf senescence. J. Exp. Bot. 48:181-199.

Buchanan-Wollaston, V., Page, T., Harrison, E., Breeze, E., Lim, P. O., Nam, H. G., Lin, J. F., Wu, S. H., Swidzinski, J., Ishizaki, K., and Leaver, C. J. 2005. Comparative transcriptome analysis reveals significant differences in gene expression and signalling pathways between developmental and dark/starvation-induced senescence in Arabidopsis. Plant J. 42:567-585.

Burkhead, J. L., Reynolds, K. A., Abdel-Ghany, S. E., Cohu, C. M., and Pilon, M. 2009. Copper homeostasis. New Phytol. 182:799-816.

Butt, A., Mousley, C., Morris, K., Beynon, J., Can, C., Holub, E., Greenberg, J. T., and Buchanan-Wollaston, V. 1998. Differential expression of a senescence-enhanced metallothionein gene in Arabidopsis in response to isolates of Peronospora parasitica and Pseudomonas syringae. Plant J. 16:209-221.

Chen, C., Ridzon, D. A., Broomer, A. J., Zhou, Z., Lee, D. H., Nguyen, J. T., Barbisin, M., Xu, N. L., Mahuvakar, V. R., Andersen, M. R., Lao, K. Q., Livak, K. J., and Guegler, K. J. 2005. Real-time quantification of microRNAs by stem-loop RT-PCR. Nucleic Acids Res. 33:e179.

Chen, W., Provart, N. J., Glazebrook, J., Katagiri, F., Chang, H. S., Eulgem, T., Mauch, F., Luan, S., Zou, G., Whitham, S. A., Budworth, P. R., Tao, Y., Xie, Z., Chen, X., Lam, S., Kreps, J. A., Harper, J. F., SiAmmour, A., Mauch-Mani, B., Heinlein, M., Kobayashi, K., Hohn, T., Dangl, J. L., Wang, X., and Zhu, T. 2002. Expression profile matrix of Arabidopsis transcription factor genes suggests their putative functions in response to environmental stresses. Plant Cell 14:559-574.

Chu, C. C., Lee, W. C., Guo, W. Y., Pan, S. M., Chen, L. J., Li, H. M., and Jinn, T. L. 2005. A copper chaperone for superoxide dismutase that confers three types of copper/zinc superoxide dismutase activity in Arabidopsis. Plant Physiol. 139:425-436.

Conti, G., Rodriguez, M. C., Manacorda, C. A., and Asurmendi, S. 2012 Transgenic expression of Tobacco mosaic virus capsid and movement proteins modulate plant basal defense and biotic stress responses in Nicotiana tabacum. Mol. Plant-Microbe Interact. 25:1370-1384.

Delaney, T. P., Uknes, S., Vernooij, B., Friedrich, L., Weymann, K., Negrotto, D., Gaffney, T., Gut-Rella, M., Kessmann, H., Ward, E., and Ryals, J. 1994. A central role of salicylic acid in plant disease resistance. Science 266:1247-1250.

Fujii, H., Chiou, T. J., Lin, S. I., Aung, K., and Zhu, J. K. 2005. A miRNA involved in phosphate-starvation response in Arabidopsis. Curr. Biol. 15:2038-2043.

Gan, S., and Amasino, R. M. 1997. Making sense of senescence (molecular genetic regulation and manipulation of leaf senescence). Plant Physiol. 113:313-319.

Golem, S., and Culver, J. N. 2003. Tobacco mosaic virus induced alterations in the gene expression profile of Arabidopsis thaliana. Mol. PlantMicrobe Interact. 16:681-688.

Gould, K. S. 2004. Nature's Swiss army knife: The diverse protective roles of anthocyanins in leaves. J. Biomed. Biotechnol. 2004:314-320.

Grosskinsky, D. K., Koffler, B. E., Roitsch, T., Maier, R., and Zechmann, B. 2012. Compartment-specific antioxidative defense in Arabidopsis against virulent and avirulent Pseudomonas syringae. Phytopathology 102:662-673.

Guo, Y., and Gan, S. 2005. Leaf senescence: Signals, execution, and regulation. Curr. Top. Dev. Biol. 71:83-112.

Guo, Y., and Gan, S. S. 2012. Convergence and divergence in gene expression profiles induced by leaf senescence and 27 senescence-promoting hormonal, pathological and environmental stress treatments. Plant Cell Environ. 35:644-655.

Hakmaoui, A., Perez-Bueno, M. L., Garcia-Fontana, B., Camejo, D., Jimenez, A., Sevilla, F., and Baron, M. 2012. Analysis of the antioxidant response of Nicotiana benthamiana to infection with two strains of Pepper mild mottle virus. J. Exp. Bot. 63:5487-5496.

Hammond-Kosack, K. E., and Jones, J. D. 1996. Resistance gene-dependent plant defense responses. Plant Cell 8:1773-1791.

Hanssen, I. M., van Esse, H. P., Ballester, A. R., Hogewoning, S. W., Parra, N. O., Paeleman, A., Lievens, B., Bovy, A. G., and Thomma, B. P.
2011. Differential tomato transcriptomic responses induced by Pepino mosaic virus isolates with differential aggressiveness. Plant Physiol. 156:301-318

Hensel, L. L., Grbic, V., Baumgarten, D. A., and Bleecker, A. B. 1993. Developmental and age-related processes that influence the longevity and senescence of photosynthetic tissues in Arabidopsis. Plant Cell 5:553-564.

Hillung, J., Cuevas, J. M., and Elena, S. F. 2012. Transcript profiling of different Arabidopsis thaliana ecotypes in response to Tobacco etch potyvirus infection. Front. Microbiol. 3:229.

Hopkins, M., Taylor, C., Liu, Z., Ma, F., McNamara, L., Wang, T. W., and Thompson, J. E. 2007. Regulation and execution of molecular disassembly and catabolism during senescence. New Phytol. 175:201-214.

Hortensteiner, S., and Feller, U. 2002. Nitrogen metabolism and remobilization during senescence. J. Exp. Bot. 53:927-937.

Huang, C. H., Kuo, W. Y., Weiss, C., and Jinn, T. L. 2012. Copper chaperone-dependent and -independent activation of three copper-zinc superoxide dismutase homologs localized in different cellular compartments in Arabidopsis. Plant Physiol. 158:737-746.

Huang, Z., Yeakley, J. M., Garcia, E. W., Holdridge, J. D., Fan, J. B., and Whitham, S. A. 2005. Salicylic acid-dependent expression of host genes in compatible Arabidopsis-virus interactions. Plant Physiol. 137:11471159

Hull, R. 2002. Matthews' Plant Virology. Elsevier Academic Press, San Diego, CA, U.S.A

Jagadeeswaran, G., Saini, A., and Sunkar, R. 2009. Biotic and abiotic stress down-regulate miR398 expression in Arabidopsis. Planta 229:1009-1014.

Jay, F., Wang, Y., Yu, A., Taconnat, L., Pelletier, S., Colot, V., Renou, J. P., and Voinnet, O. 2011. Misregulation of AUXIN RESPONSE FACTOR 8 underlies the developmental abnormalities caused by three distinct viral silencing suppressors in Arabidopsis. PLoS Pathog. 7:e1002035. Published online.

Jones-Rhoades, M. W., and Bartel, D. P. 2004. Computational identification of plant microRNAs and their targets, including a stress-induced miRNA. Mol. Cell 14:787-799.

Kachroo, P., Yoshioka, K., Shah, J., Dooner, H. K., and Klessig, D. F. 2000. Resistance to Turnip crinkle virus in Arabidopsis is regulated by two host genes and is salicylic acid dependent but NPR1, ethylene, and jasmonate independent. Plant Cell 12:677-690.

Kant, S., Peng, M., and Rothstein, S. J. 2011. Genetic regulation by NLA and microRNA827 for maintaining nitrate-dependent phosphate homeostasis in Arabidopsis. PLoS Genet. 7:e1002021. Published online.

Kim, H. J., Fonseca, J. M., Choi, J. H., Kubota, C., and Kwon, D. Y. 2008. Salt in irrigation water affects the nutritional and visual properties of romaine lettuce (Lactuca sativa L.). J. Agric. Food Chem. 56:37723776

Kim, J. H., Woo, H. R., Kim, J., Lim, P. O., Lee, I. C., Choi, S. H., Hwang, D., and Nam, H. G. 2009. Trifurcate feed-forward regulation of agedependent cell death involving miR164 in Arabidopsis. Science 323:1053-1057.

Kim, S. H., Ahn, Y. O., Ahn, M. J., Lee, H. S., and Kwak, S. S. 2012. Down-regulation of beta-carotene hydroxylase increases beta-carotene and total carotenoids enhancing salt stress tolerance in transgenic cultured cells of sweetpotato. Phytochemistry 74:69-78.

Kogovsek, P., Pompe-Novak, M., Baebler, S., Rotter, A., Gow, L., Gruden, K., Foster, G. D., Boonham, N., and Ravnikar, M. 2010. Aggressive and mild Potato virus $Y$ isolates trigger different specific responses in susceptible potato plants. Plant Pathol. 59:1121-1132.

Krecic-Stres, H., Vucak, C., Ravnikar, M., and Kovac, M. 2005. Systemic Potato virus $Y$ NTN infection and levels of salicylic and gentisic acids in different potato genotypes. Plant Pathol. 54:441-447.

Lalic, J., Agudelo-Romero, P., Carrasco, P., and Elena, S.F. 2010. Adaptation of tobacco etch potyvirus to a susceptible ecotype of Arabidopsis thaliana capacitates it for systemic infection of resistant ecotypes. Philos. Trans. R. Soc. Lond. B Biol. Sci. 365:1997-2007.

Li, J., Brader, G., and Palva, E. T. 2004. The WRKY70 transcription factor: A node of convergence for jasmonate-mediated and salicylate-mediated signals in plant defense. Plant Cell 16:319-331.

Li, J., Brader, G., Kariola, T., and Palva, E. T. 2006. WRKY70 modulates the selection of signaling pathways in plant defense. Plant J. 46:477-491.

Lim, P. O., Kim, H. J., and Nam, H. G. 2007. Leaf senescence. Annu. Rev. Plant Biol. 58:115-136.

Love, A. J., Geri, C., Laird, J., Carr, C., Yun, B. W., Loake, G. J., Tada, Y., Sadanandom, A., and Milner, J. J. 2012. Cauliflower mosaic virus protein P6 inhibits signaling responses to salicylic acid and regulates innate immunity. PLoS One 7:e47535. Published online.

Lynch, D. V., and Thompson, J. E. 1984. Lipoxygenase-mediated production of superoxide anion in senescing plant tissue. FEBS (Fed. Eur. Biochem. Soc.) Lett. 173:251-254.

Martin Martin, A., Cabrera y Poch, H. L., Martinez Herrera, D., and Ponz, 
F. 1999. Resistances to turnip mosaic potyvirus in Arabidopsis thaliana. Mol. Plant-Microbe Interact. 12:1016-1021.

Maule, A., Leh, V., and Lederer, C. 2002. The dialogue between viruses and hosts in compatible interactions. Curr. Opin. Plant Biol. 5:279-284.

Miao, Y., Laun, T., Zimmermann, P., and Zentgraf, U. 2004. Targets of the WRKY53 transcription factor and its role during leaf senescence in Arabidopsis. Plant Mol. Biol. 55:853-867.

Miller, J. D., Arteca, R. N., and Pell, E. J. 1999. Senescence-associated gene expression during ozone-induced leaf senescence in Arabidopsis. Plant Physiol. 120:1015-1024.

Munne-Bosch, S., and Alegre, L. 2002. Plant aging increases oxidative stress in chloroplasts. Planta 214:608-615.

Nagata, T., Todoriki, S., Masumizu, T., Suda, I., Furuta, S., Du, Z., and Kikuchi, S. 2003. Levels of active oxygen species are controlled by ascorbic acid and anthocyanin in Arabidopsis. J. Agric. Food Chem. 51:2992-2999.

Navabpour, S., Morris, K., Allen, R., Harrison, E., A-H-Mackerness, S. and Buchanan-Wollaston, V. 2003. Expression of senescence-enhanced genes in response to oxidative stress. J. Exp. Bot. 54:2285-2292.

Nguyen, H. D., Tomitaka, Y., Ho, S. Y., Duchene, S., Vetten, H. J., Lesemann, D., Walsh, J. A., Gibbs, A. J., and Ohshima, K. 2013. Turnip mosaic potyvirus probably first spread to Eurasian Brassica crops from wild orchids about 1000 years ago. PLoS One 8:e55336. Published online.

Pagan, I., Alonso-Blanco, C., and Garcia-Arenal, F. 2008. Host responses in life-history traits and tolerance to virus infection in Arabidopsis thaliana. PLoS Pathog. 4:e1000124. Published online.

Peng, M., Hannam, C., Gu, H., Bi, Y. M., and Rothstein, S. J. 2007. A mutation in NLA, which encodes a RING-type ubiquitin ligase, disrupts the adaptability of Arabidopsis to nitrogen limitation. Plant J. 50:320-337.

Peng, M., Hudson, D., Schofield, A., Tsao, R., Yang, R., Gu, H., Bi, Y. M., and Rothstein, S. J. 2008. Adaptation of Arabidopsis to nitrogen limitation involves induction of anthocyanin synthesis which is controlled by the NLA gene. J. Exp. Bot. 59:2933-2944.

Pfaffl, M. W., Horgan, G. W., and Dempfle, L. 2002. Relative expression software tool (REST) for group-wise comparison and statistical analysis of relative expression results in real-time PCR. Nucleic Acids Res. 30:e36.

Pic, E., de La Serve, B. T., Tardieu, F., and Turc, O. 2002. Leaf senescence induced by mild water deficit follows the same sequence of macroscopic, biochemical, and molecular events as monocarpic senescence in pea. Plant Physiol. 128:236-246.

Quirino, B. F., Noh, Y. S., Himelblau, E., and Amasino, R. M. 2000. Molecular aspects of leaf senescence. Trends Plant Sci. 5:278-282.

Rabino, I., and Mancinelli, A. L. 1986. Light, temperature, and anthocyanin production. Plant Physiol. 81:922-924.

Ramakers, C., Ruijter, J. M., Deprez, R. H., and Moorman, A. F. 2003. Assumption-free analysis of quantitative real-time polymerase chain reaction (PCR) data. Neurosci. Lett. 339:62-66.

Riefler, M., Novak, O., Strnad, M., and Schmulling, T. 2006. Arabidopsis cytokinin receptor mutants reveal functions in shoot growth, leaf senescence, seed size, germination, root development, and cytokinin metabolism. Plant Cell 18:40-54

Rolny, N., Costa, L., Carrion, C., and Guiamet, J. J. 2011. Is the electrolyte leakage assay an unequivocal test of membrane deterioration during leaf senescence? Plant Physiol. Biochem. 49:1220-1227.

Rouet, M. A., Mathieu, Y., Barbier-Brygoo, H., and Lauriere, C. 2006. Characterization of active oxygen-producing proteins in response to hypo-osmolarity in tobacco and Arabidopsis cell suspensions: Identification of a cell wall peroxidase. J. Exp. Bot. 57:1323-1332.

Ryals, J. A., Neuenschwander, U. H., Willits, M. G., Molina, A., Steiner, H. Y., and Hunt, M. D. 1996. Systemic acquired resistance. Plant Cell 8:1809-1819.

Sanchez, F., Martinez-Herrera, D., Aguilar, I., and Ponz, F. 1998. Infectivity of turnip mosaic potyvirus cDNA clones and transcripts on the systemic host Arabidopsis thaliana and local lesion hosts. Virus Res. 55:207-219.

Sanchez, F., Wang, X., Jenner, C. E., Walsh, J. A., and Ponz, F. 2003. Strains of Turnip mosaic potyvirus as defined by the molecular analysis of the coat protein gene of the virus. Virus Res. 94:33-43.

Scholthof, K. B., Adkins, S., Czosnek, H., Palukaitis, P., Jacquot, E., Hohn, T., Hohn, B., Saunders, K., Candresse, T., Ahlquist, P. Hemenway, C., and Foster, G. D. 2011. Top 10 plant viruses in molecular plant pathology. Mol. Plant Pathol. 12:938-954.

Schommer, C., Palatnik, J. F., Aggarwal, P., Chetelat, A., Cubas, P., Farmer, E. E., Nath, U., and Weigel, D. 2008. Control of jasmonate biosynthesis and senescence by miR319 targets. PLoS Biol. 6:e230. Published online.

Sharma, Y. K., and Davis, K. R. 1997. The effects of ozone on antioxidant responses in plants. Free Radic. Biol. Med. 23:480-488.
Sunkar, R., Kapoor, A., and Zhu, J. K. 2006. Posttranscriptional induction of two $\mathrm{Cu} / \mathrm{Zn}$ superoxide dismutase genes in Arabidopsis is mediated by downregulation of miR398 and important for oxidative stress tolerance. Plant Cell 18:2051-2065.

Thordal-Christensen, H., Zhang, Z., Wei, Y., and Collinge, D. B. 1997. Subcellular localization of $\mathrm{H}_{2} \mathrm{O}_{2}$ in plants. $\mathrm{H}_{2} \mathrm{O}_{2}$ accumulation in papillae and hypersensitive response during the barley-powdery mildew interaction. Plant J. 11:1187-1194.

Torres, M. A. 2010. ROS in biotic interactions. Physiol. Plant. 138:414 429.

Tourino, A., Sánchez, F., Fereres, A., and Ponz, F. 2008. High expression of foreign proteins from a biosafe viral vector derived from Turnip mosaic virus. Spanish J. Agric. Res. 1:48-58

Tsuda, K., Sato, M., Glazebrook, J., Cohen, J. D., and Katagiri, F. 2008. Interplay between MAMP-triggered and SA-mediated defense responses. Plant J. 53:763-775.

Uknes, S., Mauch-Mani, B., Moyer, M., Potter, S., Williams, S., Dincher, S., Chandler, D., Slusarenko, A., Ward, E., and Ryals, J. 1992. Acquired resistance in Arabidopsis. Plant Cell 4:645-656.

Ulker, B., Shahid Mukhtar, M., and Somssich, I. E. 2007. The WRKY70 transcription factor of Arabidopsis influences both the plant senescence and defense signaling pathways. Planta 226:125-137.

Vernooij, B., Uknes, S., Ward, E., and Ryals, J. 1994. Salicylic acid as a signal molecule in plant-pathogen interactions. Curr. Opin. Cell Biol. 6:275-279.

Vlot, A. C., Dempsey, D. A., and Klessig, D. F. 2009. Salicylic Acid, a multifaceted hormone to combat disease. Annu. Rev. Phytopathol. 47:177-206.

Wang, S. D., Zhu, F., Yuan, S., Yang, H., Xu, F., Shang, J., Xu, M. Y., Jia, S. D., Zhang, Z. W., Wang, J. H., Xi, D. H., and Lin, H. H. 2011. The roles of ascorbic acid and glutathione in symptom alleviation to SAdeficient plants infected with RNA viruses. Planta 234:171-181.

Weaver, L. M., Gan, S., Quirino, B., and Amasino, R. M. 1998. A comparison of the expression patterns of several senescence-associated genes in response to stress and hormone treatment. Plant Mol. Biol. 37:455-469.

Whitham, S. A., Yang, C., and Goodin, M. M. 2006. Global impact: Elucidating plant responses to viral infection. Mol. Plant-Microbe Interact. 19:1207-1215.

Whitham, S. A., Quan, S., Chang, H. S., Cooper, B., Estes, B., Zhu, T. Wang, X., and Hou, Y. M. 2003. Diverse RNA viruses elicit the expression of common sets of genes in susceptible Arabidopsis thaliana plants. Plant J. 33:271-283.

Wohlgemuth, H., Mittelstrass, K., Kschieschan, S., Bender, J., Weigel, H.J., Overmeyer, K., Kangasjarvi, J., Sandermann, H., and Langebartels, G. 2002. Activation of an oxidative burst is a general feature of sensitive plants exposed to the air pollutant ozone. Plant Cell Environ. 717726.

Wu, A., Allu, A. D., Garapati, P., Siddiqui, H., Dortay, H., Zanor, M. I., Asensi-Fabado, M. A., Munne-Bosch, S., Antonio, C., Tohge, T., Fernie, A. R., Kaufmann, K., Xue, G. P., Mueller-Roeber, B., and Balazadeh, S. 2012. JUNGBRUNNEN1, a reactive oxygen species-responsive NAC transcription factor, regulates longevity in Arabidopsis. Plant Cell 24:482-506.

Xiong, Y., Contento, A. L., and Bassham, D. C. 2005. AtATG18a is required for the formation of autophagosomes during nutrient stress and senescence in Arabidopsis thaliana. Plant J. 42:535-546.

Yamasaki, H., Abdel-Ghany, S. E., Cohu, C.M., Kobayashi, Y., Shikanai, T., and Pilon, M. 2007. Regulation of copper homeostasis by microRNA in Arabidopsis. J. Biol. Chem. 282:16369-16378.

Yamasaki, H., Hayashi, M., Fukazawa, M., Kobayashi, Y., and Shikanai, T. 2009. SQUAMOSA promoter binding protein-like7 is a central regulator for copper homeostasis in Arabidopsis. Plant Cell 21:347-361.

Yang, C., Guo, R., Jie, F., Nettleton, D., Peng, J., Carr, T., Yeakley, J. M., Fan, J. B., and Whitham, S. A. 2007. Spatial analysis of Arabidopsis thaliana gene expression in response to Turnip mosaic virus infection. Mol. Plant-Microbe Interact. 20:358-370.

Yuan, S., and Lin, H. H. 2008. Role of salicylic acid in plant abiotic stress. Z. Naturforsch. C 63:313-320.

Zhang, W., Gao, S., Zhou, X., Chellappan, P., Chen, Z., Zhou, X., Zhang, X., Fromuth, N., Coutino, G., Coffey, M., and Jin, H. 2011. Bacteriaresponsive microRNAs regulate plant innate immunity by modulating plant hormone networks. Plant Mol. Biol. 75:93-105.

\section{AUTHOR-RECOMMENDED INTERNET RESOURCES}

fgStatistics vs. 2009 website: sites.google.com/site/fgStatistics GraphPad software: www.graphpad.com 